\title{
Constitutive IKK2 activation in intestinal epithelial cells induces intestinal tumors in mice
}

\author{
Katerina Vlantis, ${ }^{1}$ Andy Wullaert, ${ }^{1}$ Yoshiteru Sasaki, ${ }^{2,3}$ Marc Schmidt-Supprian, ${ }^{2,4}$ \\ Klaus Rajewsky, ${ }^{2}$ Tania Roskams, ${ }^{5}$ and Manolis Pasparakis' \\ ${ }^{1}$ Institute for Genetics, Center for Molecular Medicine (CMMC), and Cologne Excellence Cluster on Cellular Stress Responses in Aging-Associated Diseases (CECAD), \\ University of Cologne, Cologne, Germany. 2 Immune Disease Institute, Boston, Massachusetts, USA. ${ }^{3 R I K E N ~ C e n t e r ~ f o r ~ D e v e l o p m e n t a l ~ B i o l o g y, ~}$ \\ Laboratory for Stem Cell Biology, Kobe, Japan. ${ }^{4}$ Max Planck Institute of Biochemistry, Martinsried, Germany. \\ ${ }^{5}$ Department of Pathology, University Hospitals, University of Leuven, Leuven, Belgium.
}

\begin{abstract}
Many cancers display increased NF- $\kappa B$ activity, and NF- $\kappa B$ inhibition is known to diminish tumor development in multiple mouse models, supporting an important role of NF- $\kappa B$ in carcinogenesis. NF- $\kappa B$ activation in premalignant or cancer cells is believed to promote tumor development mainly by protecting these cells from apoptosis. However, it remains unclear to what extent NF- $\kappa B$ activation exhibits additional protumorigenic functions in premalignant cells that could be sufficient to induce spontaneous tumor development. Here we show that expression of constitutively active IKB kinase 2 (IKK2ca) in mouse intestinal epithelial cells (IECs) induced spontaneous tumors in aged mice and also strongly enhanced chemical- and Apc mutation-mediated carcinogenesis. IECs expressing IKK2ca displayed altered Wnt signaling and increased proliferation and elevated expression of genes encoding intestinal stem cell-associated factors including Ascl2, Olfm4, DLK1, and $\mathrm{Bmi}-1$, indicating that increased IKK2/NF- $\mathrm{KB}$ activation synergized with Wnt signaling to drive intestinal tumorigenesis. Moreover, IECs expressing IKK2ca produced cytokines and chemokines that induced the recruitment of myeloid cells and activated stromal fibroblasts to become myofibroblasts, thus creating a tumor-promoting microenvironment. Taken together, our results show that constitutively increased activation of IKK2/NF- $\mathrm{KB}$ signaling in the intestinal epithelium is sufficient to induce the full spectrum of cell-intrinsic and stromal alterations required for intestinal tumorigenesis.
\end{abstract}

\section{Introduction}

The IкB kinase (IKK)/NF- $\kappa B$ signaling pathway controls the expression of many genes regulating immune and inflammatory responses, cell survival, and proliferation and is believed to be centrally involved in carcinogenesis. Many cancer cell lines, but also primary tumors, display constitutively increased NF-KB activity, and inhibition of NF- $\mathrm{KB}$ compromises the survival and growth of cultured cancer cells, suggesting that NF-KB is important for the survival of at least some types of tumors (1). Furthermore, NF- $\mathrm{KB}$ inhibition diminished tumor development in mouse models, supporting an important role for NF-KB in carcinogenesis (2-6).

IKK2/IKK $\beta$-mediated NF-KB activation was proposed to provide a link between inflammation and carcinogenesis by acting both in cancer cells and in cells of the microenvironment to promote tumor development $(7,8)$. IKK2 ablation in myeloid cells reduced the expression of cytokines and growth factors supporting tumor growth and diminished tumor development in the azoxymethane/dextran sulfate sodium (AOM/DSS) mouse model of carcinogen-initiated inflammation-associated colon cancer (5). In addition, NF-KB activation in cancer-associated fibroblasts was recently shown to be important for skin carcinogenesis by coordinating the expression of fibroblast-derived proinflammatory factors promoting macrophage recruitment, neovascularization, and tumor growth (9). These studies demonstrated that NF- $\mathrm{KB}$ promotes carcinogenesis by acting in cells of the tumor microen-

Conflict of interest: The authors have declared that no conflict of interest exists. Citation for this article: J Clin Invest. 2011;121(7):2781-2793. doi:10.1172/JCI45349. vironment to induce the expression of factors supporting tumor growth. In line with its well-established prosurvival functions, IKK2 ablation in colonic or gastric epithelial cells reduced the incidence of AOM/DSS-induced colon cancer (5) and carcinogen $\mathrm{N}$-methyl-N-nitrosourea-induced (MNU-induced) gastric cancer

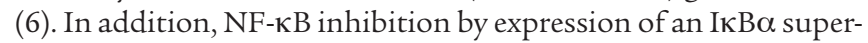
repressor (I $\mathrm{I} B \alpha-\mathrm{SR})$ or by ablation of p65/RelA in lung epithelial cells reduced the incidence of oncogenic Ras-induced lung cancer $(4,10)$. However, NF-кB inhibition in skin or liver cells had opposite effects in different models of carcinogenesis. NF-кB inhibition by expression of IKB $\alpha$-SR in epidermal keratinocytes synergized with oncogenic Ras to induce epidermal cancer (11) or led to spontaneous tumor development (12), while IKK2 ablation in melanocytes protected mice from oncogenic Ras-induced

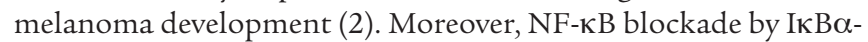
SR expression in hepatocytes inhibited inflammation-associated liver cancer development in the Mdr2-deficient mouse model (3), while IKK2 ablation in hepatocytes sensitized mice to chemical hepatocarcinogenesis induced by diethylnitrosamine (DEN) (13). Finally, liver parenchymal cell-specific knockout of NEMO/IKK $\gamma$ led to the spontaneous development of hepatocellular carcinomas in mice (14). These findings suggest that the role of IKK/NF-кB signaling within premalignant or tumor cells in carcinogenesis is complex and often depends on the specific tissue studied and the carcinogenic stimulus applied. These results also indicate that $\mathrm{NF}-\kappa \mathrm{B}$ activation in premalignant or tumor cells is likely to affect different processes that are fundamental for carcinogenesis in addition to its antiapoptotic function. 
A

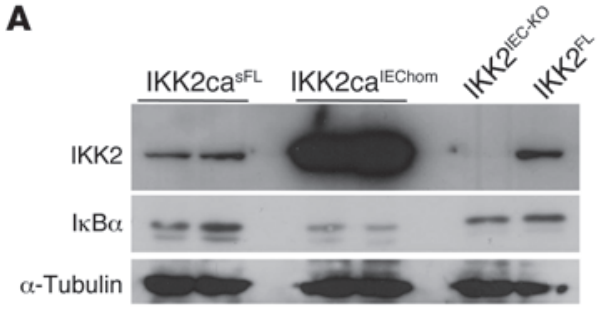

C

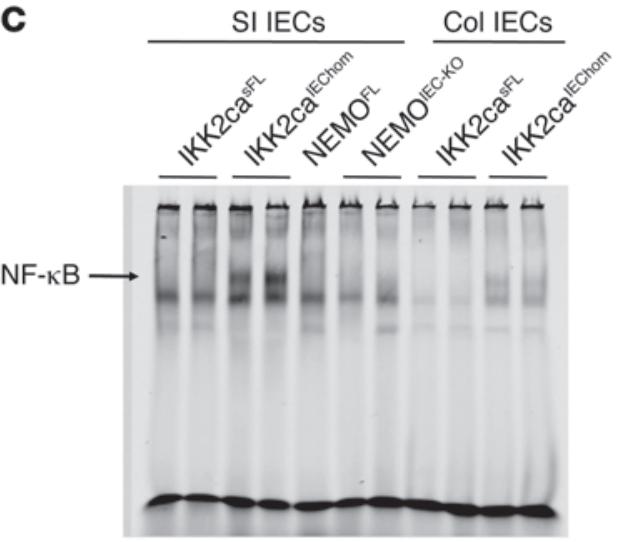

B

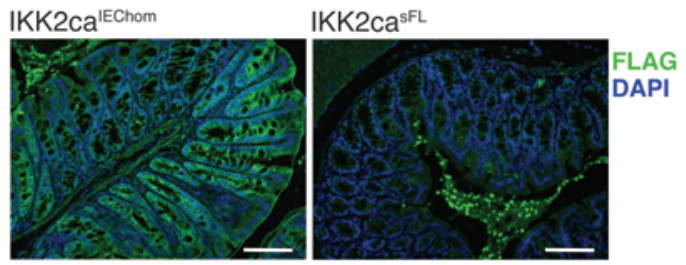

D

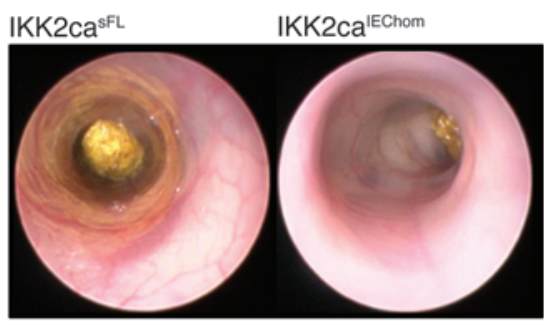

E

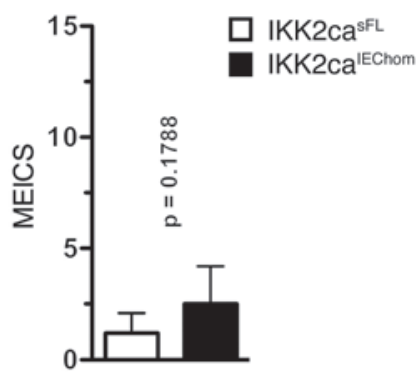

$\mathbf{F}$

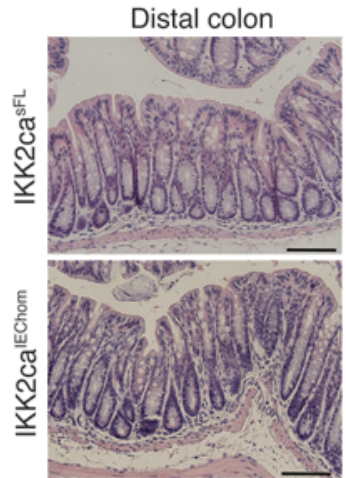

Proximal colon
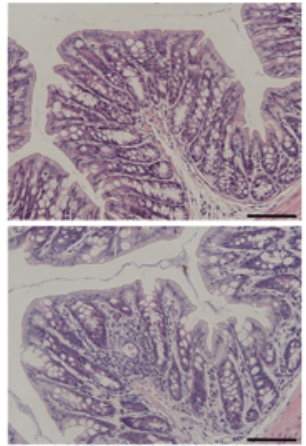

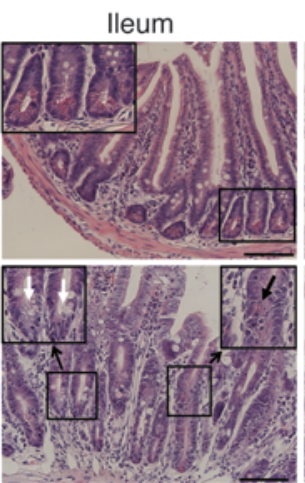

Jejunum

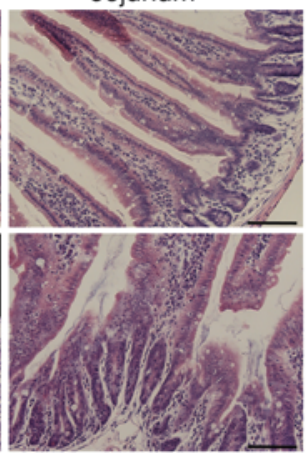

Figure 1

IKK2ca expression in IECs induces NF-KB activation and mild intestinal inflammation. (A) Immunoblot reveals increased IKK2 expression and reduced levels of $\mathrm{IKB}_{\mathrm{K}} \mathrm{in} \mathrm{SI} \mathrm{IEC}$ from IKK2calEChom mice compared with IKK2cas littermates. (B) Immunofluorescent staining with anti-FLAG antibodies shows IEC-specific expression of FLAG-IKK2ca in IKK2ca ${ }^{\mathrm{IEChom}}$ colon sections. Background staining in the lumen of the IKK2casFL colon results from incomplete removal of luminal contents. (C) EMSA reveals increased NF-KB DNA-binding activity in nuclear extracts from IKK2calEChom SI and colonic IECs. (D) Representative endoscopic images of colons from 8-week-old IKK2ca ${ }^{\mathrm{sFL}}$ and IKK2caIEChom mice. (E) Quantification of MEICS showing no significant colonic inflammation in 7- to 9-week-old IKK2calEChom $(n=10)$ mice compared with IKK2casFL $(n=5)$ littermates. Data are presented as mean \pm SD. (F) H\&E-stained sections show crypt elongation and increased immune cell infiltration in the SI and colon of IKK2cal ${ }^{\mathrm{IEChom}}$ compared with IKK2casFL mice. Note the lack of Paneth cells in ileal crypts in IKK2calEChom mice (indicated by white arrows in inset). The black arrow indicates a mislocalized Paneth cell. Scale bars: $50 \mu \mathrm{m}$.

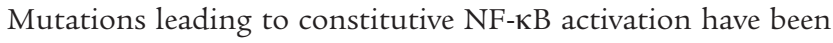
found in several cancers $(1,15-17)$, suggesting that persistent activation of NF- $\kappa \mathrm{B}$ could be a critical step in tumor development, although the mechanisms by which cell-intrinsic NF-KB activation promotes tumorigenesis remain incompletely understood. Most importantly, it remains unclear whether constitutive NF-кB activation is sufficient to induce spontaneous tumor development in vivo. Here we used a transgenic mouse model expressing constitutively active IKK2 specifically in intestinal epithelial cells (IECs) to study the mechanisms by which constitutively increased NF- $\mathrm{KB}$ activation affects intestinal tumorigenesis. Our results show that persistent NF-KB activation strongly synergizes with chemical and genetic models of intestinal carcinogenesis to induce tumors in both the colon and the small intestine (SI). Most importantly, mice expressing constitutively active IKK2 in IECs spontaneously developed tumors in the colon and the SI, demonstrating that persistent activation of IKK2/NF- $\kappa \mathrm{B}$ signaling in IECs is sufficient to induce intestinal tumorigenesis.

\section{Results}

Constitutive IKK2/NF-КB activation in IECs induced mild inflammation in the colon and SI. To study in vivo the epithelial-intrinsic role of $\mathrm{NF}-\kappa \mathrm{B}$ in intestinal tumorigenesis, we generated mice expressing 
A
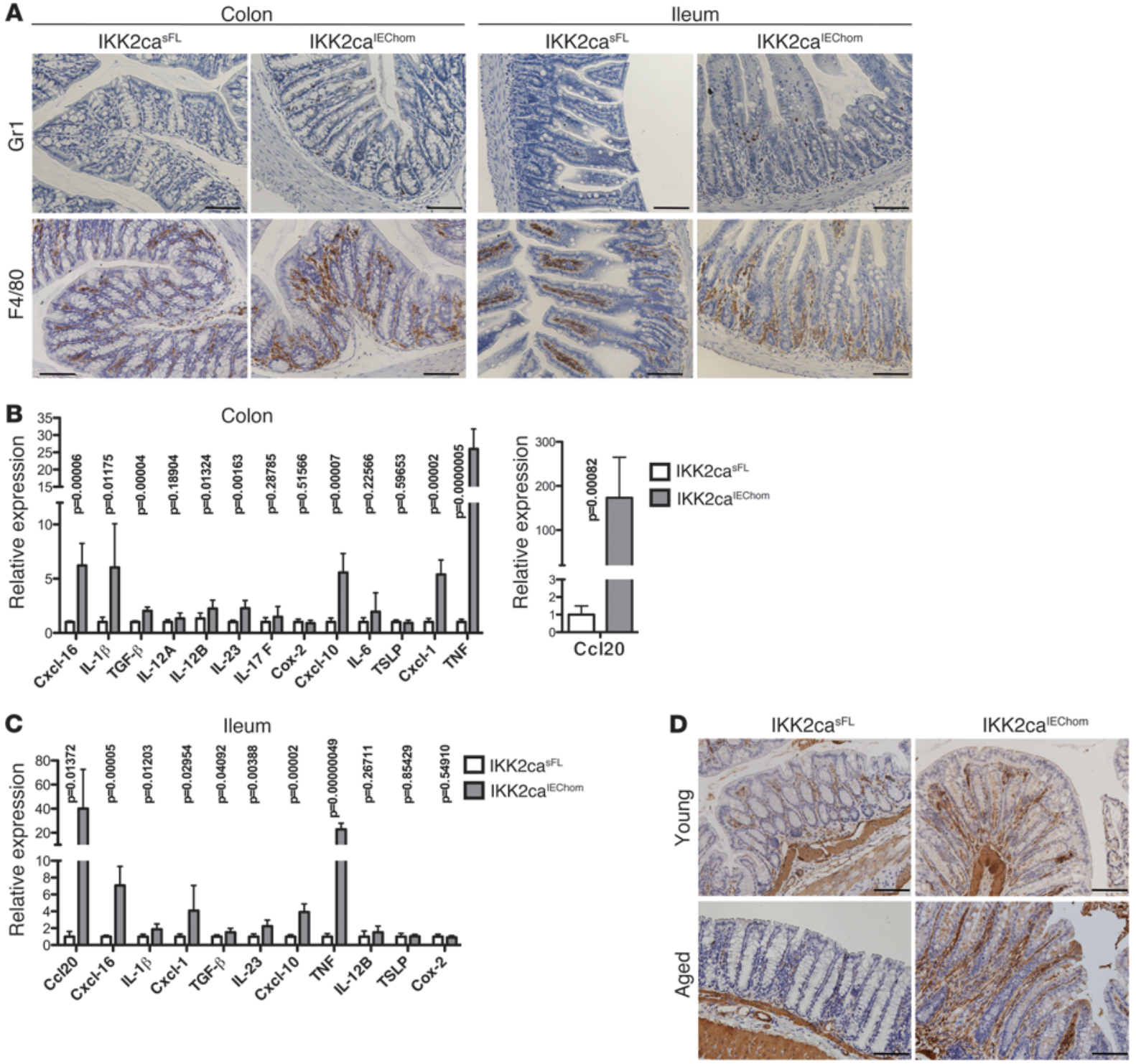

\section{Figure 2}

Immune cell infiltration and increased cytokine and chemokine expression in the gut of IKK2ca IEChom mice. (A) Immunohistochemical staining for Gr1 and F4/80 reveals increased numbers of granulocytes and macrophages, respectively, in colonic and SI cross sections of 6-week-old IKK2caIEChom mice. In the SI of IKK2calEChom mice, F4/80-positive cells accumulated around the crypts, while in control mice, macrophages were mainly found in the villi. (B and C) qRT-PCR analysis shows enhanced expression of a subset of proinflammatory genes in the colon (B) and the ileum (C) of 7- to 8-week-old IKK2calEChom mice ( $n \geq 6$ for each genotype; mRNA levels are presented as mean \pm SD). (D) Immunohistochemical staining with antibodies recognizing $\alpha$-SMA revealed the presence of increased numbers of activated myofibroblasts in colons of young (10 week old) and aged (1 year old) IKK2calEChom mice compared with IKK2casFL littermates. Scale bars: $50 \mu \mathrm{m}$.

constitutively active IKK2 (IKK2ca) specifically in IECs by crossing mice carrying the R26-StopFLIkk2ca (IKK2 $\mathrm{ca}^{\mathrm{sFL}}$ ) allele (18) with villin-Cre transgenics (19). Homozygous mice expressing 2 copies of the R26-StopFLIkk2ca allele (IKK2 $\mathrm{ca}^{\text {IEChom})}$ expressed high levels of IKK2ca specifically in IECs (Figure 1, A and B; Supplemental Figure 1A and Supplemental Figure 2A; supplemental material available online with this article; doi:10.1172/JCI45349DS1) and showed increased NF- $\kappa \mathrm{B}$ activation, as assessed by I $\mathrm{I} B \alpha$ immunoblot of total protein extracts and by EMSA on nuclear extracts from colonic and SI primary epithelial cells (Figure 1, A and C, and Supplemental Figure 1B). Heterozygous mice carrying 1 copy of the R26-StopFLIkk2ca allele (IKK2 $\mathrm{ca}^{\text {IEChet}) ~ e x p r e s s e d ~ a b o u t ~ h a l f ~}$ the levels of IKK2 $\mathrm{ca}$ and also showed elevated NF- $\mathrm{KB}$ activation in IECs (Supplemental Figure 1). IKK2ca-expressing IECs showed normal levels of IKK1, NEMO, and p65, but increased expression of $\mathrm{p} 100$ and RelB, which are produced by NF- $\mathrm{BB}-$ regulated genes

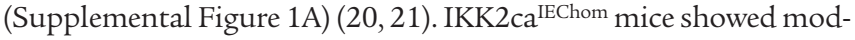
erately reduced body weight (Supplemental Figure 2B), prompting us to assess whether they developed spontaneous intestinal disease. Endoscopic analysis of 7- to 9-week-old animals did not reveal signs

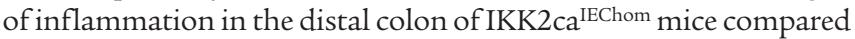
with littermate controls (Figure 1, D and E). Colon length did not 
differ; however, the SIs of IKK2 $\mathrm{ca}^{\mathrm{IEChom}}$ mice were markedly elongated compared with those of littermate controls (Supplemental Figure 2, C-E). Histological examination of colon and SI cross sections revealed the presence of scattered areas showing signs of mild focal inflammation, with small numbers of immune cells infiltrating the colonic mucosa and the area around the crypts in the SI (Figure $1 \mathrm{~F}$ ). The epithelium adjacent to these inflammatory infiltrates showed slightly altered morphology with moderately elongated crypts, particularly in the enlarged SI (Figure 1F). Goblet cell numbers in the colon and SI did not differ between IKK2 $\mathrm{ca}^{\mathrm{IEChom}}$ and control mice. However, we detected decreased numbers of Paneth cells in SI crypt bases, while sometimes mislocalized Paneth cells were found higher up toward the luminal side in elongated crypts (Figure 1F), suggesting that increased IKK2/NF- $\mathrm{KB}$ activity in IECs alters Paneth cell differentiation or localization.

To characterize the inflammatory infiltrates in the intestinal mucosa of IKK $2 \mathrm{ca}^{\mathrm{IEChom}}$ mice, we performed immunohistochemical staining with specific antibodies recognizing macrophages, granulocytes, $\mathrm{T}$ cells, and B cells. F4/80 staining revealed areas showing moderately increased numbers of macrophages in sections from the colon but also from the SI of IKK $2 \mathrm{ca}^{\text {IEChom }}$ mice, where they appeared to accumulate around the base of the crypts (Figure $2 \mathrm{~A}$ ). In addition, small numbers of $\mathrm{Gr} 1^{+}$granulocytes were detected in the ileum and to a lesser extent in the colon of IKK $2 \mathrm{ca}^{\text {IEChom }}$ but not in control mice (Figure $2 \mathrm{~A}$ ). B and $\mathrm{T}$ cell numbers in the gut did not differ considerably between IKK2 $\mathrm{ca}^{\text {IEChom }}$ and control mice (data not shown). Quantitative RT-PCR (qRT-PCR) analysis on mRNA from colon and ileum revealed increased expression of several proinflammatory cytokines and chemokines including TNF, IL-1 $\beta, \mathrm{Ccl} 20, \mathrm{Cxcl}-1$, Cxcl-10, and Cxcl-16 in IKK2 $\mathrm{ca}^{\mathrm{IEChom}}$ mice (Figure 2, B and C). Immunoblot analysis also revealed increased IL-1 $\beta$ protein levels in the colon and SI of IKK2 $\mathrm{ca}^{\text {IEChom }}$ mice (Supplemental Figure $3, \mathrm{C}$ and D). TNF, IL-1 $\beta, \mathrm{Ccl} 20$, Cxcl-10, and Cxcl-16 were also upregulated in primary colonic and SI IECs (Supplemental Figure 3 , A and B), suggesting that they are directly induced by IKK2ca expression in epithelial cells. Immunohistochemical staining with antibodies recognizing $\alpha$-SMA, a marker of activated myofibroblasts (9), revealed increased activation of stromal fibroblasts in the intestinal mucosa of aged but also young IKK $2 \mathrm{ca}^{\text {IEChom }}$ mice (Figure 2D). Thus, IKK2ca expression in IECs results in increased cytokine and chemokine expression, recruitment of myeloid cells, and activation of stromal fibroblasts in the intestinal mucosa.

Expression of IKK2ca in IECs strongly enhanced chemical carcinogeninduced intestinal tumor development. Because partial inhibition of canonical NF- $\mathrm{KB}$ signaling by IEC-specific knockout of IKK2 or p65 sensitized mice to DSS-induced colitis $(5,22)$, we reasoned that increased IKK2ca-mediated NF- $\mathrm{KB}$ activation in epithelial cells might protect mice from DSS-induced intestinal injury. Surprisingly, IKK2 $\mathrm{ca}^{\mathrm{IEChom}}$ mice developed more severe colitis manifesting with pronounced weight loss, intestinal bleeding, and diarrhea after DSS treatment (Figure 3A and data not shown). Histological examination revealed tissue damage with extended loss of crypt structures and increased inflammatory cell infiltration in colons from IKK2 $\mathrm{ca}^{\mathrm{IEChom}}$ compared with IKK2 $\mathrm{ca}^{\mathrm{sFL}}$ mice (Figure 3B). In addition, colons from DSS-treated IKK2 $\mathrm{ca}^{\mathrm{IEChom}}$ mice showed increased expression of proinflammatory cytokines and chemokines including TNF, IL-1 $\beta$, Cxcl-1, and MCP-1 (Figure 3C). Thus, constitutive NF-кB activation in IECs exacerbated colitis development in response to DSS-induced epithelial injury.
To determine whether constitutive NF-кB activation in IECs affects inflammation-associated colon cancer, we assessed AOM/ DSS-induced carcinogenesis in IKK2 $\mathrm{ca}^{\mathrm{IEChom}}$ and control mice (Figure $4 \mathrm{~A}$ ). Since IKK2 $\mathrm{ca}^{\text {IEChom }}$ mice were very sensitive to DSS treatment, we applied a modified protocol including only 1 short cycle of treatment with low DSS concentration (1.5\% DSS for 3 days). This treatment induced severe weight loss associated with intestinal bleeding and diarrhea in IKK2 $\mathrm{ca}^{\mathrm{IEChom}}$ but not in control mice (Figure 4A and data not shown). Moreover, endoscopic analysis performed 26 days after AOM injection revealed signs of severe colitis in IKK2 $\mathrm{ca}^{\mathrm{IEChom}}$ but not in IKK2 $\mathrm{ca}^{\mathrm{sFL}}$ mice (Figure 4B). Endoscopy on day 65 revealed that all IKK2 $\mathrm{ca}^{\mathrm{IEChom}}$, but none of their IKK2 $\mathrm{ca}^{\mathrm{sFL}}$ littermates, had developed multiple tumors in the distal colon (Figure 4C), which displayed histological characteristics typical of mucus-producing adenomas with advanced dysplasia (Figure 4D) and in some cases progressed to adenocarcinomas invading the submucosa (Figure 4E). Thus, IEC-specific expression of IKK2ca had a strong protumorigenic effect resulting in the development of multiple broad-based colonic adenomas even under a very mild $\mathrm{AOM} / \mathrm{DSS}$ protocol that was not sufficient to induce tumors in control mice. The extreme sensitivity of IKK2 $\mathrm{ca}^{\mathrm{IEChom}}$ mice to DSSinduced colon inflammation most likely contributed to the strongly enhanced tumorigenesis observed in these animals upon AOM/DSS treatment. Greten et al. showed previously that epithelial-specific ablation of IKK2 also sensitized mice to DSS-induced injury resulting in increased colon inflammation; however, these mice showed reduced AOM/DSS-induced tumor development (5). Therefore, while both inhibition and increased activation of IKK2 in the intestinal epithelium sensitized mice to DSS, resulting in increased colon inflammation, they differentially affected AOM/DSS-induced colon cancer development, suggesting that IKK2 exerts important cellintrinsic functions in IECs that are critical for tumorigenesis.

To uncouple the potential epithelial intrinsic protumorigenic functions of IKK2ca from its effects in DSS-induced colitis, we investigated whether constitutive IKK2/NF-KB activity also affects carcinogenesis induced by repeated AOM injections in the absence of DSS, a model of carcinogen-induced colon cancer that does not depend on inflammation-mediated tumor promotion $(23,24)$. $\mathrm{IKK} 2 \mathrm{ca}^{\mathrm{IEChom}}$ and IKK2 $\mathrm{ca}^{\mathrm{sFL}}$ littermates received 5 weekly injections of AOM, and colon cancer development was evaluated 13 weeks after the first injection. Whereas IKK2 $\mathrm{ca}^{\mathrm{sFL}}$ controls did not develop intestinal tumors with this protocol, all IKK2 $\mathrm{ca}^{\text {IEChom }}$ mice developed multiple broad-based adenomas with hyperplasia and early dysplasia in the colon, but also showed hyperplastic crypts with shortened villus structures in the SI (Figure 4F). Thus, constitutively increased IKK2 activity in IECs strongly synergized with AOM-induced mutagenesis to induce intestinal tumorigenesis.

Constitutive IKK2/NF- $\mathrm{K} B$ activation strongly synergized with Wnt signaling to promote intestinal tumorigenesis. Most intestinal cancers display increased activation of the Wnt signaling pathway, and mutations activating Wnt signaling cause intestinal tumors in humans and mice (25). The adenomatous polyposis coli gene encoding the APC tumor suppressor, an essential component of the multiprotein complex negatively regulating $\beta$-catenin activation, is frequently mutated in human intestinal cancers, and APC mutations cause intestinal tumors in mice (25-28). To assess whether constitutive IKK2/NF-KB activity in IECs affects APC mutation-induced tumorigenesis, we crossed the IKK2 $\mathrm{ca}^{\mathrm{IEC}}$ mice with Apc1638N mice, which bear a truncated Apc allele and spontaneously develop adenomatous polyps in the proximal part of the SI at an age of 6 to 9 months (29). 

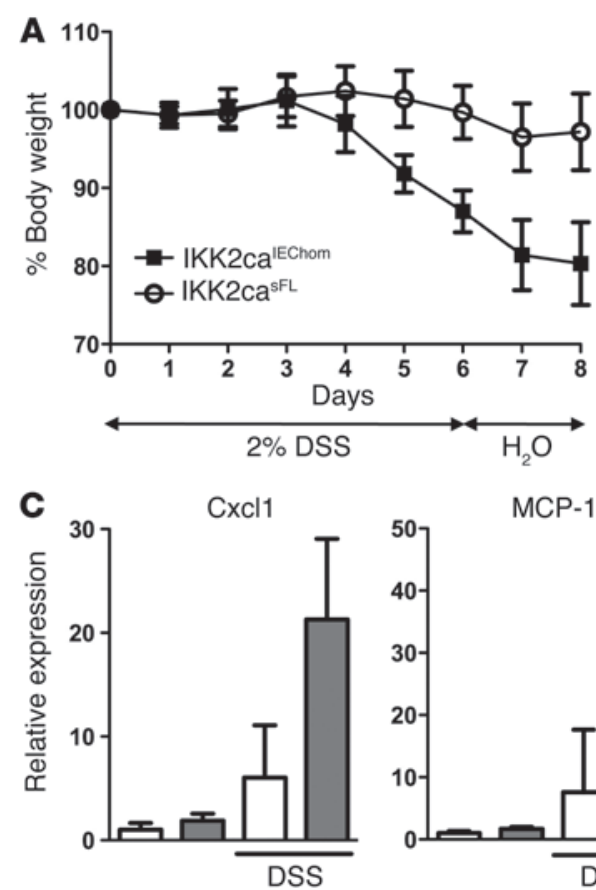

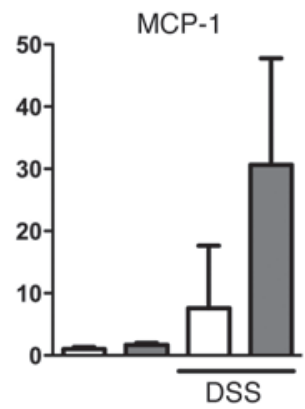

B
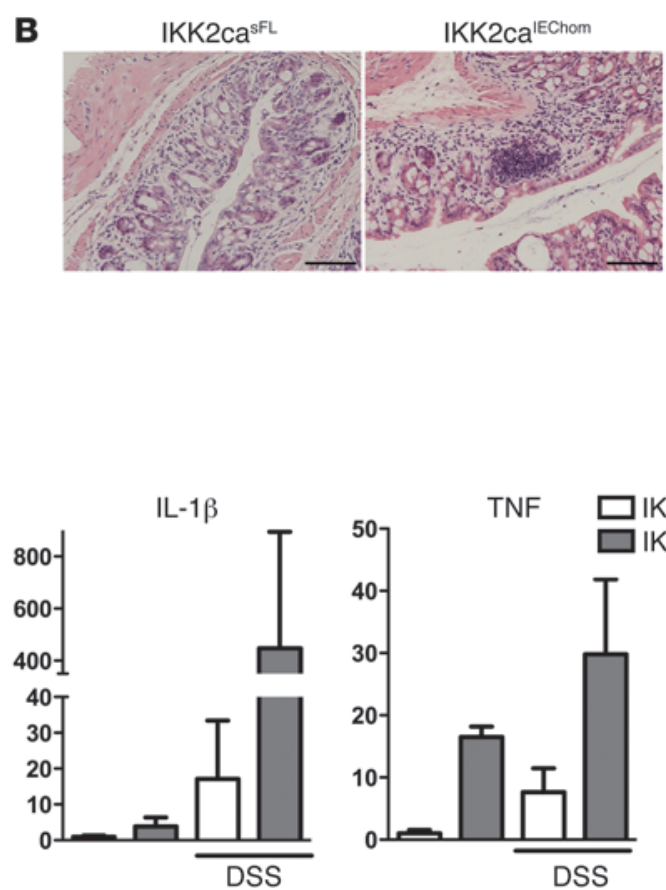

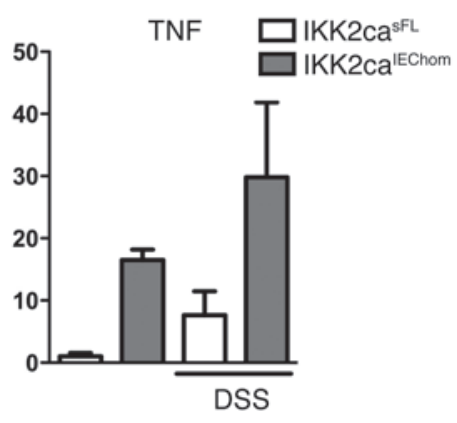

Figure 3

IKK2calEChom mice exhibit increased sensitivity to DSS-induced colitis. (A) IKK2calEChom mice showed more severe weight loss compared with littermate controls in response to administration of $2 \%$ DSS ( $n \geq 10$ per genotype; data represent mean \pm SD). (B) Histological cross sections of the distal colon of mice sacrificed on day 8 showed moderate epithelial damage and inflammation in IKK2ca ${ }^{\mathrm{sFL}}$ animals, while IKK2caIEChom mice showed strong inflammation and extended tissue damage in the colonic mucosa. (C) qRT-PCR demonstrating increased expression of proinflammatory factors in distal colons of DSS-treated IKK2calEChom mice compared with IKK2ca ${ }^{\text {sFL }}$ controls (naive mice, $n=5$ per genotype; DSS-treated mice, $n=10$ per genotype; mRNA levels are presented as mean \pm SD). Scale bars: $50 \mu \mathrm{m}$.

Endoscopic and macroscopic analysis of intestines from 4-month-old animals revealed the presence of multiple polyps in both the colon and the proximal half of the SI of Apc1638N/IKK2 $\mathrm{ca}^{\text {IEChet }}$ mice (Figure $5 \mathrm{~A}$ and data not shown). In contrast, only 2 out of $6 \mathrm{Apc} 1638 \mathrm{~N}$ mice harbored 1 to 2 small polyps in the proximal SI, while none of the IKK2 $\mathrm{ca}^{\mathrm{sFL}}$ or IKK2 $\mathrm{ca}^{\text {IEChet }}$ littermate controls showed intestinal tumors (Figure 5A). Histological analysis of colon sections revealed the presence of adenomas containing dysplastic crypts with undifferentiated multilayered epithelium in Apc1638N/IKK2 $\mathrm{ca}^{\mathrm{IEChet}}$ mice (Figure 5B). In addition, SI sections showed the presence of adenomatous polyps containing aberrantly shaped dysplastic crypts with stratified undifferentiated epithelium in Apc1638N/IKK2 $\mathrm{ca}^{\text {IEChet }}$ mice (Figure 5B). Tumors in the colon and SI from Apc1638N/IKK2ca $\mathrm{ca}^{\mathrm{IECh}}$ mice showed strongly increased proliferation as assessed by Ki67 immunohistochemistry (IHC) (Figure 5C). In addition, all epithelial cells in dysplastic crypts from Apc1638N/IKK2 $\mathrm{ca}^{\text {IEChet }}$ mice showed strong nuclear staining for the transcription factor Sox9, a $\beta$-catenin/ TCF4-target gene that is normally highly expressed in crypt stem cells and at lower levels in transit amplifying (TA) cells, Paneth cells, and enteroendocrine cells, but is absent from differentiated absorptive enterocytes (refs. 30, 31, and Figure 5D). In contrast, epithelial cells in Apc1638N or IKK2 $\mathrm{ca}^{\text {IEChet }}$ mice did not show increased proliferation or Sox9 expression compared with those in control animals (Figure 5D and Supplemental Figure 4). Thus, constitutive IKK2 activation in IECs strongly synergized with the Apc1638N mutation to enhance tumorigenesis, resulting in early development of highly proliferative dysplastic adenomatous lesions displaying increased $\beta$-catenin activation in Apc1638N/IKK2 ca ${ }^{\text {IEChet mice. }}$
Spontaneous tumor development in the colon and SI of aged IKK2calEChom mice. Our results showed that epithelial-specific expression of IKK2ca strongly enhanced tumorigenesis in different inflammation-dependent, carcinogen-induced, and genetic models of intestinal cancer, suggesting that constitutively increased IKK2 activity in IECs promotes tumor development by affecting fundamental cellular processes important for intestinal carcinogenesis. To address whether constitutively increased IKK2 activity was sufficient to induce the spontaneous development of intestinal tumors, we followed a cohort of IKK $2 \mathrm{ca}^{\mathrm{IEChom}}$ and littermate control mice over a period of 12 months and assessed tumor development by endoscopy and postmortem macroscopic and histological examination. During the course of this experiment, we noticed that a fraction of the aging IKK $2 \mathrm{ca}^{\mathrm{IEChom}}$ animals showed pronounced weight loss and diarrhea, occasionally accompanied by rectal prolapse and bleeding, and were sacrificed before the age of 12 months. Histopathological analysis of tissues from these IKK2 $\mathrm{ca}^{\text {IEChom }}$ animals showed thickening of the bowel wall in both the SI and colon and revealed the presence of hyperplastic and sometimes dysplastic crypts, indicating that IKK2ca expression induces intestinal tumors (data not shown). Endoscopic analysis revealed colon inflammation in nearly all IKK2 $\mathrm{ca}^{\mathrm{IEChom}}$ mice that reached 1 year of age and the presence of large tumors in the distal colon in about $50 \%$ of these animals (Figure 6, A and B). Histologically, these tumors showed a thickened inflamed mucosa with hyperplastic aberrant crypt growth and in some cases also dysplastic crypts characterized by loss of differentiation and epithelial 
A

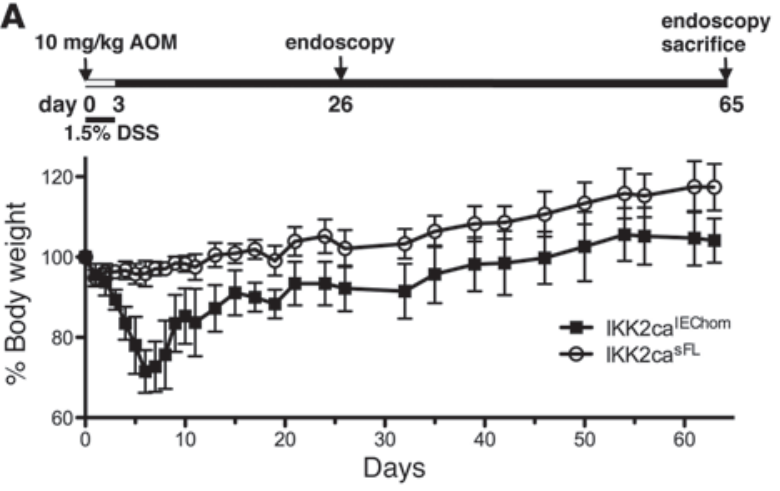

D
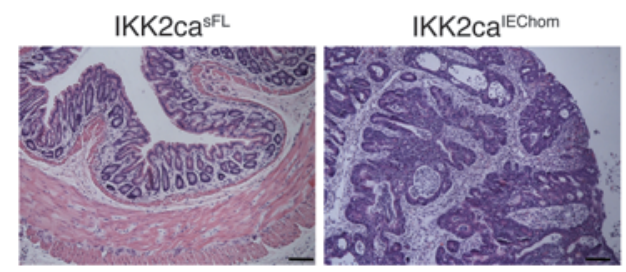

B

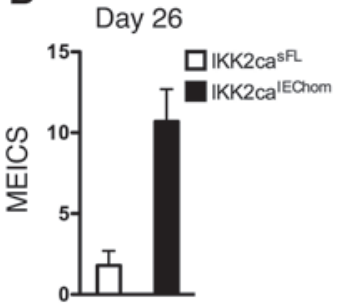

C

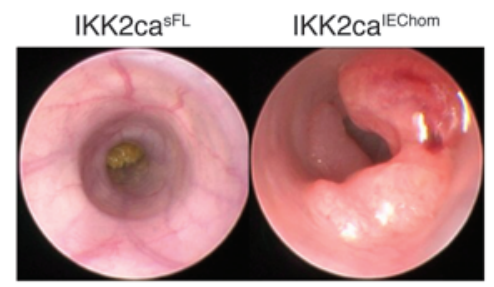

E

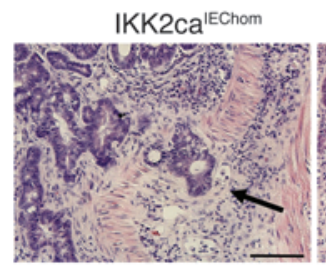

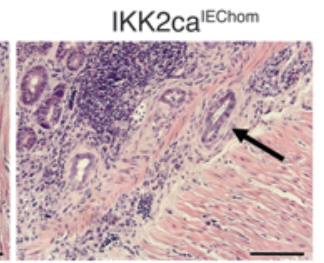

$\mathbf{F}$

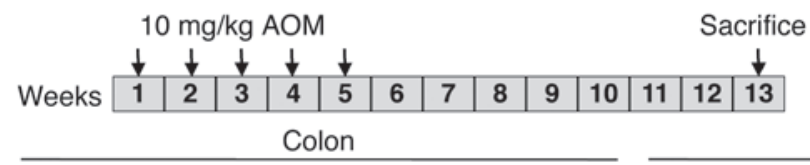

Small intestine
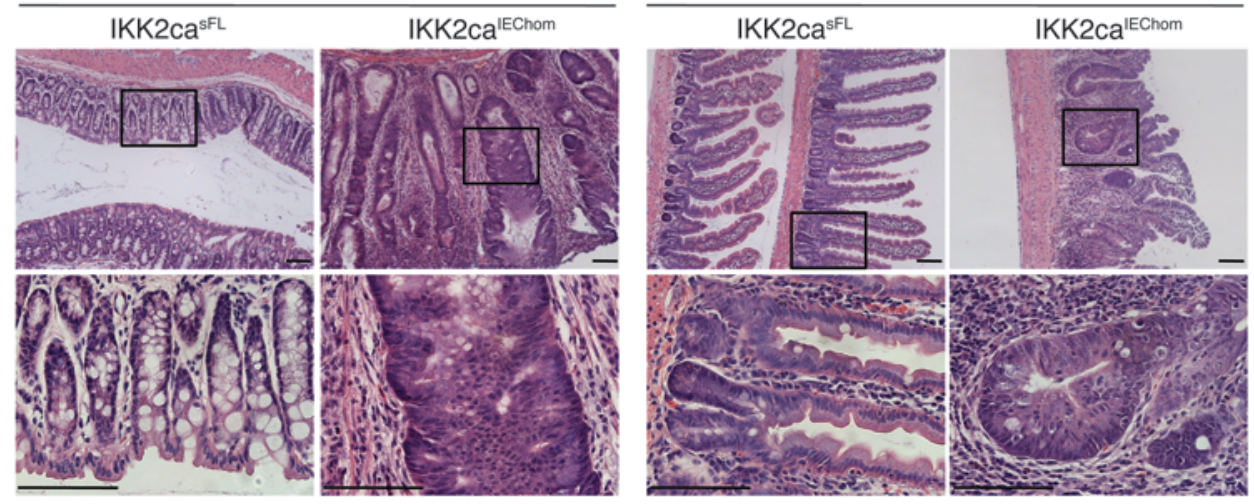

Figure 4

IKK2calEChom mice display strongly enhanced tumorigenesis in response to AOM treatments. (A) IKK2calEChom and IKK2casFL mice were injected with $10 \mathrm{mg} / \mathrm{kg} \mathrm{AOM}$ and given $1.5 \%$ DSS in drinking water for 3 days followed by regular drinking water ( $n \geq 9$ per genotype; data shown as mean \pm SD). (B) MEICS determined on day 26 revealed severe colon inflammation in IKK2 calEChom but not in IKK2 $\mathrm{Ca}^{\mathrm{SFL}}$ mice $(n \geq 6$ per genotype; data shown as mean \pm SD). (C) Endoscopic analysis on day 65 revealed pronounced tumor formation in the distal colons of IKK2calEChom but not in IKK2ca ${ }^{\mathrm{sFL}}$ mice. (D) Histological analysis of colon cross sections revealed the presence of advanced adenomas showing loss of epithelial cell differentiation and epithelial stratification in IKK2ca EChom mice. In contrast, the colonic mucosa of IKK2ca ${ }^{\mathrm{sFL}}$ mice appeared normal. (E) Histological tissue sections from AOM/DSS-treated IKK2caIEChom mice showing colonic adenocarcinomas as identified by invasion of epithelial tissue into the submucosa (indicated by arrows). (F) IKK2calEChom and IKK2casFL mice $(n \geq 8)$ received 5 weekly injections of $10 \mathrm{mg} / \mathrm{kg}$ AOM and were sacrificed 13 weeks after the first injection. Histological cross sections revealed the presence of tumors displaying pronounced epithelial hyperplasia and early dysplastic lesions in both colon and SI of IKK2calEChom but not IKK2 $\mathrm{ca}^{\mathrm{SFL}}$ mice. Scale bars: $50 \mu \mathrm{m}$.

stratification (Figure 6C). From $17 \mathrm{IKK} 2 \mathrm{ca}^{\mathrm{IEChom}}$ mice examined at the age of 1 year, we found early hyperplastic adenomas in 10 animals and in 6 of those we detected also more advanced adenomatous lesions with epithelial dysplasia. Histological analysis of the SI revealed lesions with abnormal crypt architecture and increased crypt numbers indicating epithelial hyperproliferation in 7 out of $14 \mathrm{IKK} 2 \mathrm{ca}^{\mathrm{IEChom}}$ mice, 4 of which also showed the growth of adenomatous polyps with signs of early dysplasia (Figure 6C). Ki67 staining revealed strong hyperproliferation of epithelial cells in tumors from the colon and SI of IKK2 $\mathrm{ca}^{\mathrm{IEChom}}$ mice (Figure 6D). In addition, all epithelial cells in dysplastic crypts showed strong expression of Sox9, indicating activation of $\beta$-catenin in these cells (Figure 6D). Collectively, these results demonstrate that constitutively increased IKK2 activity in premalignant IECs was sufficient to induce the spontaneous development of tumors displaying increased proliferation and $\beta$-catenin activation in the colon and to a lesser extent also in the SI of IKK2 $\mathrm{ca}^{\mathrm{IEChom}}$ mice. 

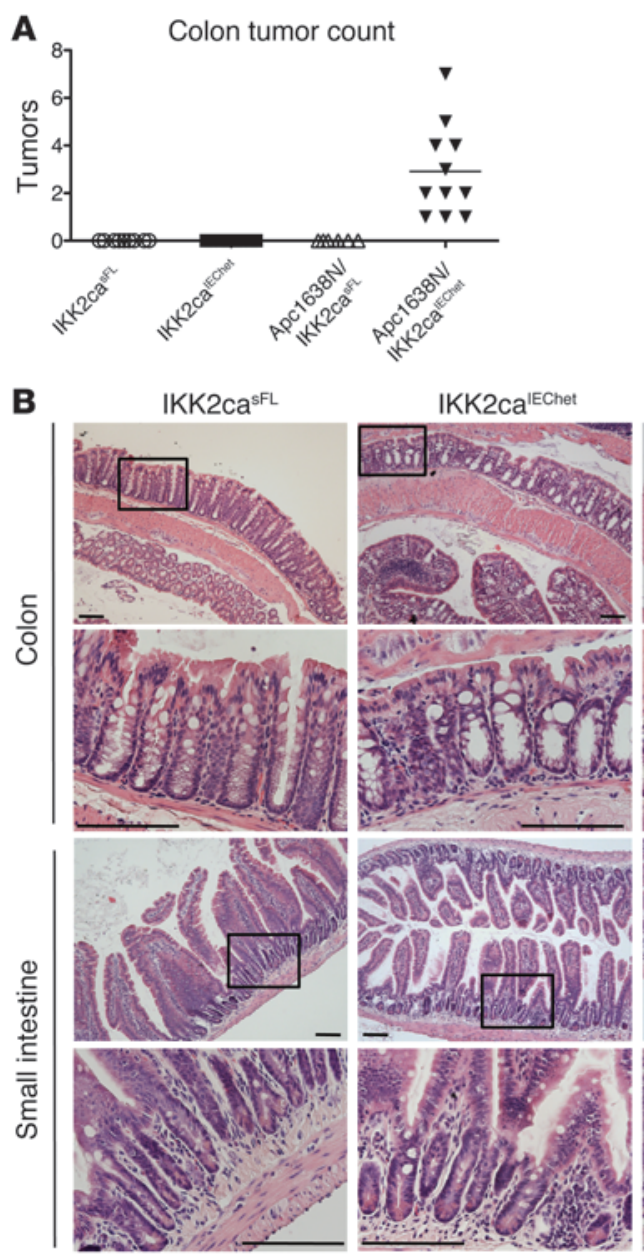

C

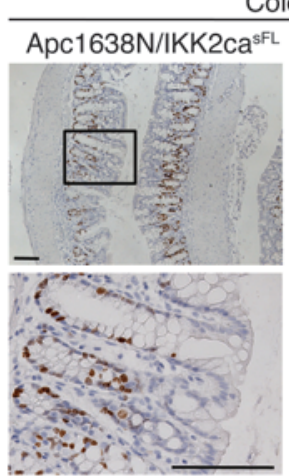

Colon

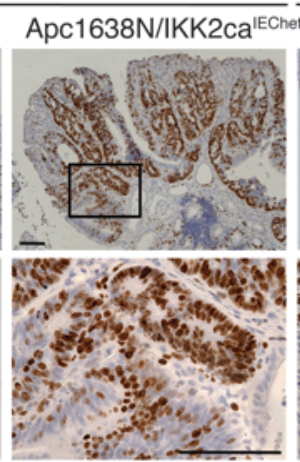

D

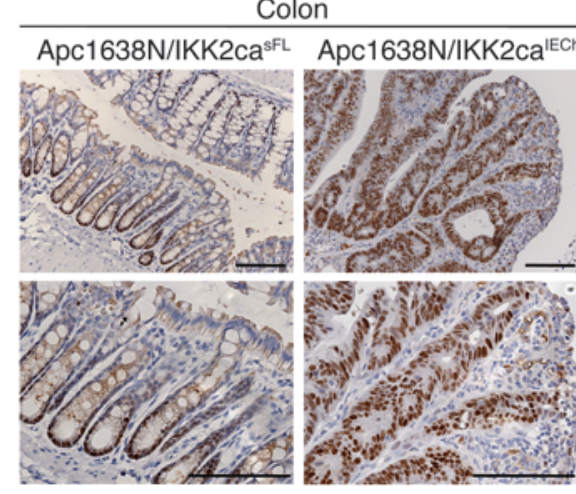

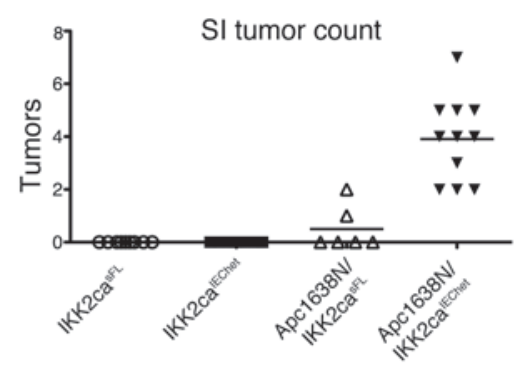

Apc1638N//KK2ca ${ }^{\text {sFL }} \quad$ Apc1638N/IKK2caEChet
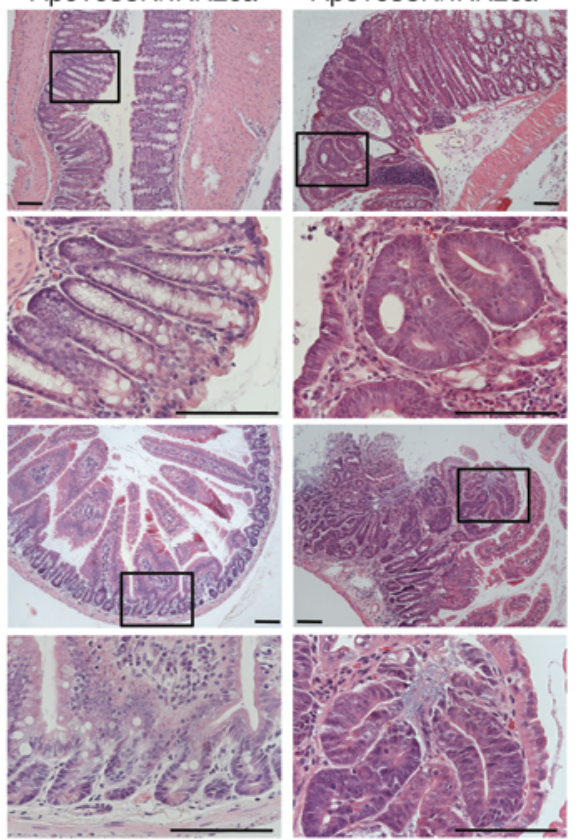

Small intestine
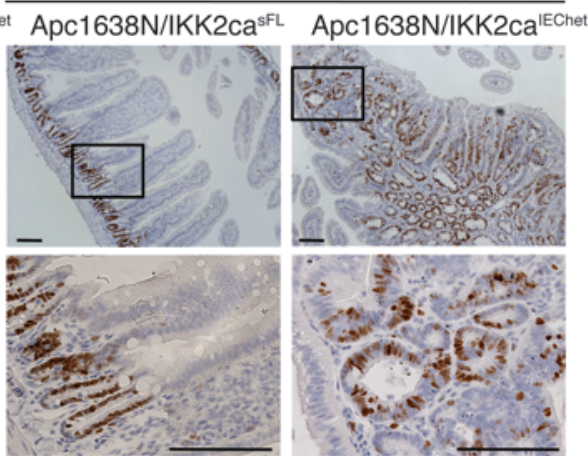

Small intestine

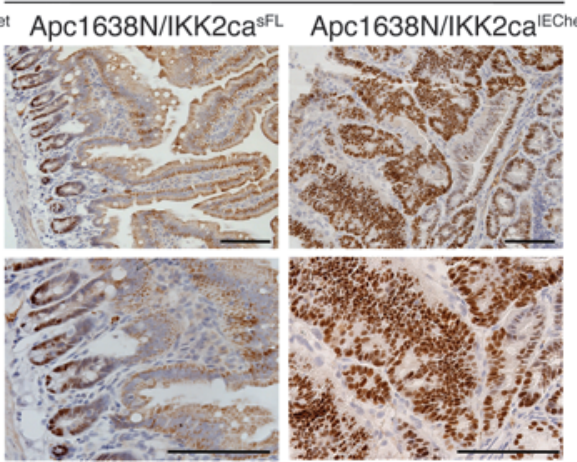

\section{Figure 5}

Heterozygous IKK2ca expression in IECs strongly enhances tumorigenesis in Apc1638N mice and results in early tumor formation in the colon and the SI. (A) Macroscopic analysis of intestines from 4-month-old mice showed that all Apc1638N/IKK2calEChet mice examined $(n=11)$ had developed at least 1 macroscopically visible tumor in the colon and also multiple clearly identifiable polyps in the proximal half of the SI. Littermate Apc1638N/IKK2ca ${ }^{\mathrm{sFL}}$ mice $(n=6)$ did not show colon tumors, while only 2 out of 6 animals examined bore 1 or 2 small polyps in the pyloric region of the SI. IKK2casFL $(n=9)$ and IKK2calEChet $(n=11)$ mice did not show tumors in either the colon or the SI. (B) Histological analysis of colon sections from Apc1638N/IKK2calEChet mice revealed the presence of tumors showing hyperplastic and dysplastic crypts with multilayered undifferentiated epithelium. Histological analysis of proximal SI sections from Apc1638N/IKK2calEChet mice revealed the growth of polyps that harbored aberrantly shaped, dysplastic crypts showing epithelial stratification and lack of differentiation. Histological analysis of colon and SI sections from IKK2calEChet and IKK2casFL littermates did not reveal the presence of tumors. (C) Immunostaining for Ki67 revealed increased proliferation of epithelial cells in adenomas from the colon and SI of Apc1638N/IKK2ca IEChet mice, whereas Apc1638N/IKK2casFL mice showed a normal Ki67 staining pattern. (D) Immunohistochemical analysis revealed strong Sox9 expression in all epithelial cells in colonic and SI tumors in Apc1638N/IKK2calEChet mice. In contrast, Apc1638N/IKK2casFL mice showed normal Sox9 staining, with Sox9-positive IECs in the base of the crypts and the transit-amplifying compartment in both tissues. Scale bars: $50 \mu \mathrm{m}$. 
Increased $\beta$-catenin activity and perturbation of the stem cell compartment in the intestine of IKK2 $\mathrm{ca}^{I E C h o m}$ mice. To investigate the early mechanisms by which IKK2ca expression drives intestinal tumorigenesis, we examined colonic and SI tissue from 8 -week-old IKK2 $\mathrm{ca}^{\text {IEChom }}$ animals for activation of the $\beta$-catenin pathway. Immunohistochemical analysis of $\beta$-catenin revealed increased presence of active $\beta$-catenin in both cytoplasmic and nuclear extracts from colonic IECs from IKK2 $\mathrm{ca}^{\mathrm{IEChom}}$ mice (Figure 7A). Consistent with the increased $\beta$-catenin activation, immunostaining for Ki67 revealed increased epithelial cell proliferation in transgenic colonic crypts with an extension of the Ki67-positive nuclei toward the lumen indicative for an expanded TA cell compartment (Figure 7B). Interestingly, all SI crypt epithelial cells were $\mathrm{Ki}^{2} 7^{+}$in IKK2 $\mathrm{ca}^{\mathrm{IEChom}}$ mice, in contrast to the welldefined proliferation pattern of control crypts where Ki67 stained TA cells and only occasionally cells in the base of the crypts, where Paneth cells and the rarely dividing intestinal epithelial stem cells are located $(32,33)$. In line with this observation, crypts in the SI and colon of IKK $2 \mathrm{ca}^{\text {IEChom }}$ mice showed an expansion of the Sox9-expressing epithelial cell compartment, suggesting increased $\beta$-catenin transcriptional activity (Figure $7 C$ ). Despite the increased epithelial proliferation, the Wnt-regulated c-myc and cyclin D1 genes were not upregulated in IKK2ca-expressing IECs (Supplemental Figure 5C). However, MMP7, also known to be transcriptionally regulated by $\beta$-catenin (34), was expressed at higher levels in epithelial cells from IKK2 $\mathrm{ca}^{\mathrm{IEChom}}$ mice (Supplemental Figure $5 \mathrm{C}$ ). Therefore, some but not all $\beta$-catenin target genes were induced in IKK2ca-expressing IECs. Sox9 negatively regulates Wnt-induced expression of c-myc and cyclin D1 (35); therefore, increased Sox 9 expression might be responsible for the fact these genes are not upregulated in IKK2ca-expressing IECs.

SI crypts in IKK2 $\mathrm{ca}^{\mathrm{sFL}}$ mice showed the expected Sox 9 expression pattern with stem cells, identified as cells located at the bottom of the crypt characterized by a slim cytoplasmic rim and elongated triangular nuclei, and Paneth cells, identified by their small round nuclei and large cytoplasm, strongly stained with anti-Sox9 antibodies (36). In contrast, the Sox9 staining pattern in the SI from IKK2 $\mathrm{ca}^{\mathrm{IEChom}}$ mice did not allow the clear identification of Paneth cells or stem cells in crypt bases (Figure 7C). Furthermore, crypt fission events, which are thought to occur only upon stem cell duplication, were regularly observed in IKK2 $\mathrm{ca}^{\mathrm{IEChom}}$ but not in control mice. These observations indicated that the differentiation or proliferation status of crypt stem cells, which have been identified as the cells of origin of intestinal cancer (37), might be altered already in premalignant intestinal crypts of IKK2 $\mathrm{ca}^{\mathrm{IEChom}}$ mice. Indeed, analysis of genes known to be expressed in intestinal epithelial stem cells (31) showed strong upregulation of Ascl2 and Olfm 4 and moderate increase in CD44 and TnfRsF19 expression in the colon from 7- to 8-week-old IKK2 $\mathrm{ca}^{\text {IEChom }}$ mice (Figure 7D). Ascl2, CD44, and Bmi-1 were also upregulated in the SI from these animals (Figure 7E). Olfm4, Bmi-1, and CD44 were previously shown to be regulated by NF-KB (38-40), and we also found that the promoter of Ascl 2 contains a consensus NF- $\kappa B$ site (data not shown), suggesting that constitutively increased IKK2/NF-KB activity might directly regulate the intestinal stem cell compartment by inducing the expression of NF-אB target genes encoding stem cell-associated factors. The expression of DLK1 (also called Pref1), a protein that is best known for its role in preventing progenitor cell differentiation in different tissues (41) and has been implicated in colon carcinogenesis (42), was also strongly upregulated in both the colon and SI from IKK2 $\mathrm{ca}^{\mathrm{IEChom}}$ mice (Figure 7F). Thus, several stem cell-associated factors are upregulated in the intestine of IKK2 $\mathrm{ca}^{\mathrm{IEChom}}$ mice and could be implicated in the development of spontaneous tumors in this model.

\section{Discussion}

Many cancers display constitutive activation of NF-אB signaling, indicating that NF- $\mathrm{KB}$ activation is an important event during tumor development affecting fundamental cellular processes that are critical for carcinogenesis. NF- $\kappa \mathrm{B}$ activation in early initiated or malignant tumor cells is believed to perform mainly antiapoptotic functions (17). However, it remains unclear whether constitutive $\mathrm{NF}-\kappa \mathrm{B}$ activation in premalignant cells performs additional protumorigenic functions that are critical for carcinogenesis. In this context, it is not known whether cell-intrinsic NF- $\mathrm{BB}$ activation is sufficient to induce spontaneous tumor development.

Here we show that expression of constitutively active IKK2 in IECs not only strongly synergizes with chemical and genetic models of intestinal carcinogenesis, but also is sufficient to induce the spontaneous development of tumors in both the colon and the SI. Our studies suggest that sustained IKK2 activation in IECs drives intestinal tumorigenesis by exerting both cell-intrinsic and paracrine functions. IKK2 activation in epithelial cells induced the expression of several proinflammatory cytokines and chemokines that are important for intestinal carcinogenesis. It is noteworthy that although IKK2ca expression strongly activated NF- $\mathrm{BB}$ signaling in IECs, only a subset of the known NF-кB-regulated cytokines and chemokines were upregulated. For example, IL-6, a well-known $\mathrm{NF}-\kappa \mathrm{B}-$ inducible cytokine that has been implicated in colorectal carcinogenesis (43-45), was not upregulated in IKK2 $\mathrm{ca}^{\mathrm{IEChom}}$ mice. In contrast, TNF and IL-1 $\beta$ were upregulated in both the SI and colon of IKK $2 \mathrm{ca}^{\mathrm{IEChom}}$ mice, and given their important function in the regulation of intestinal inflammation and carcinogenesis (46, 47), they are likely to be implicated in IKK2ca-mediated intestinal tumor development. The most highly upregulated gene in IKK2caexpressing IECs was CCL20, a chemokine that has been reported to induce tumor cell growth and migration in human colorectal cancer (48). Another chemokine that was highly induced in the intestine of IKK2 $\mathrm{ca}^{\mathrm{IEChom}}$ mice is Cxcl-16, which together with its receptor Cxcr6 has been suggested to promote inflammation-associated tumor development (49). Therefore, IKK2ca expression in IECs induces the expression of specific cytokines and chemokines with important protumorigenic activities.

Increased numbers of macrophages and granulocytes, but not T or B lymphocytes, were detected in the mucosa of young mice, suggesting that increased cytokine and chemokine expression by IECs initiated an innate immune response driven by myeloid cells. Infiltrating macrophages were found mainly surrounding the base of the crypts in the colon and SI of IKK $2 \mathrm{ca}^{\text {IEChom }}$ mice. Since intestinal tumors originate from crypt stem cells, increased myeloid cell infiltration in this area is likely to contribute to the spontaneous development of intestinal tumors in IKK $2 \mathrm{ca}^{\mathrm{IEChom}}$ mice by creating a microenvironment supporting tumor growth. In addition to immune cells, stromal fibroblasts that are activated to become myofibroblasts constitute an important component of the tumor-supporting microenvironment (50). We detected the presence of increased numbers of $\alpha$-SMA-expressing activated myofibroblasts in close proxim-

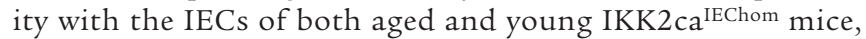
suggesting that stromal fibroblasts are activated already at a 
A

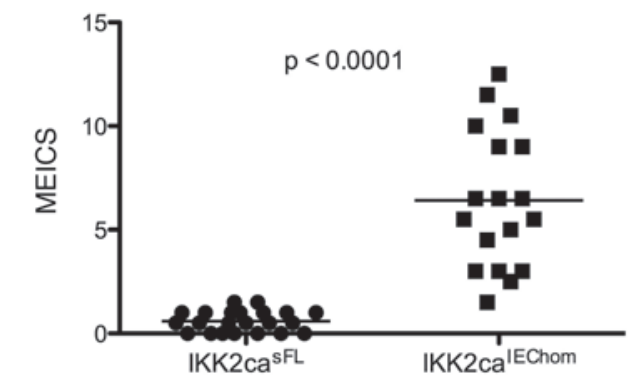

C
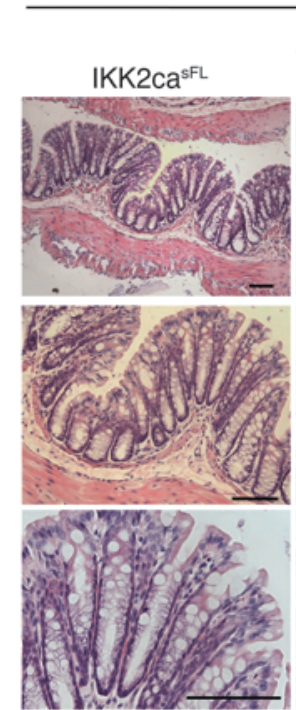

D

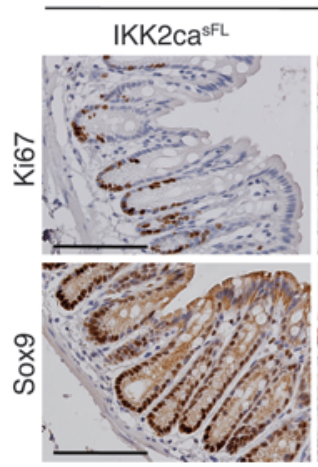

Colon
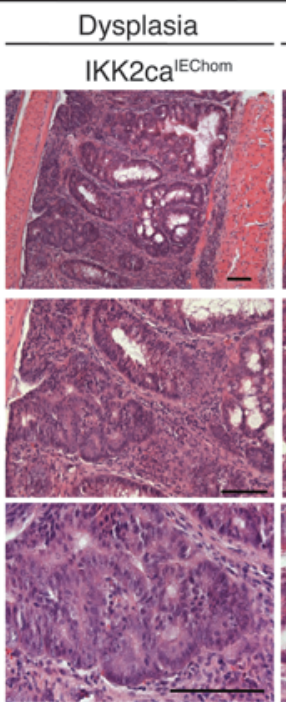

Colon

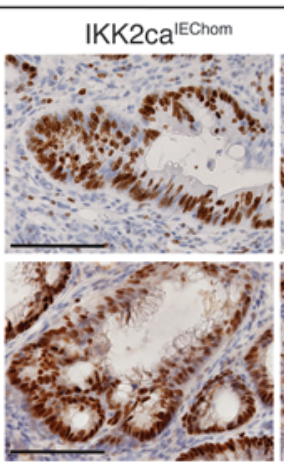

B

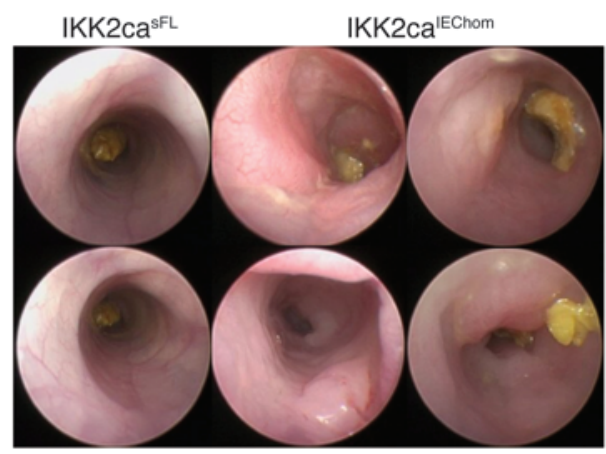

Small intestine

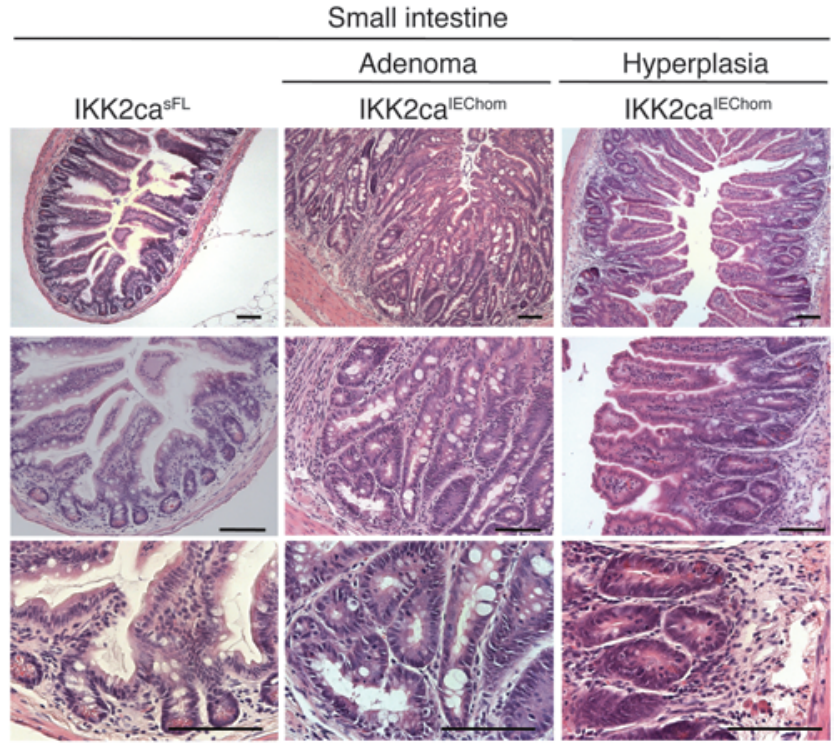

Small intestine

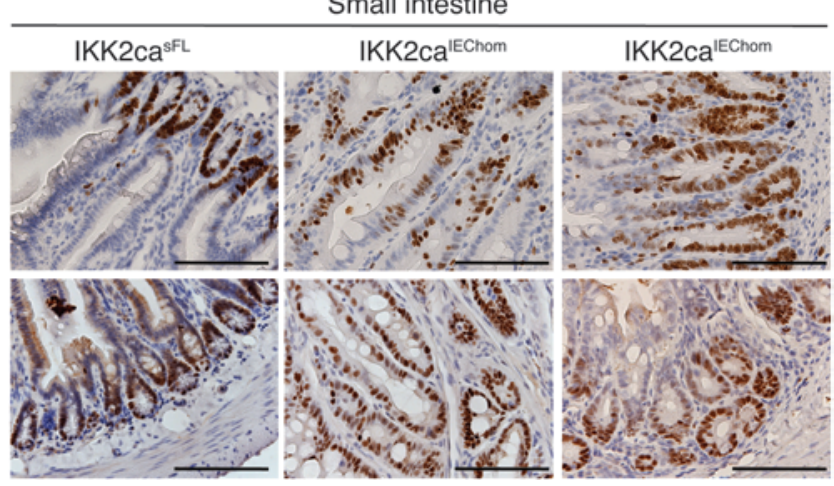

\section{Figure 6}

IKK2calEChom mice spontaneously develop intestinal tumors. (A) Aged ( $\geq 48$ week old) IKK2calEChom mice showed endoscopically detectable colon inflammation, reflected by a heightened MEICS. (B) Representative endoscopic pictures of 1-year-old IKK2caIEChom mice, showing the presence of tumors exhibiting pronounced vascularization in the distal colon. IKK2casL littermates did not show colon inflammation or tumors. (C) Histological analysis of colon cross sections showed the presence of tumors in 10 out of 17 animals examined, characterized by thickening of the mucosa, epithelial hyperplasia, aberrantly formed crypts, and inflammation. (D) Immunostaining for Ki67 showed strongly increased proliferation of epithelial cells in dysplastic and hyperplastic lesions in the colon and SI from IKK2calEChom mice. Immunostaining for Sox9 also revealed strongly increased Sox9 expression in epithelial cells in colonic and SI tumors. IKK2casFL littermates showed normal Ki67 and Sox9 staining in the colon and SI. Scale bars: $50 \mu \mathrm{m}$.

very early stage and could contribute to intestinal tumor initiation and progression in this model. Cytokines secreted by IKK2ca-expressing IECs are likely to induce the differentiation of stromal fibroblasts to tumor-supporting myofibroblasts.
Indeed, proinflammatory cytokines such as IL-1 $\beta$ were previously shown to activate stromal fibroblasts to support tumor initiation and growth (9). Therefore, constitutive activation of IKK2/NF-KB signaling in IECs acts in a paracrine manner 


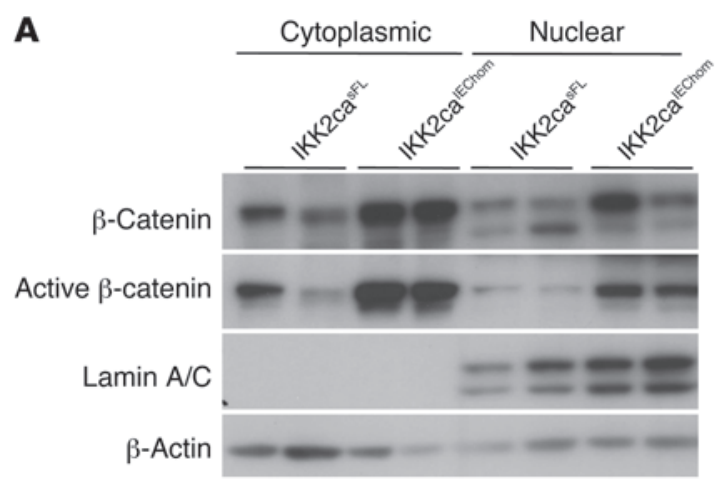

B
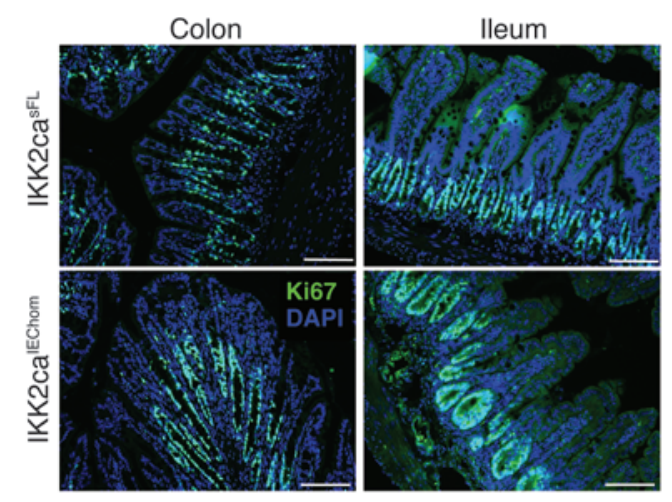

C

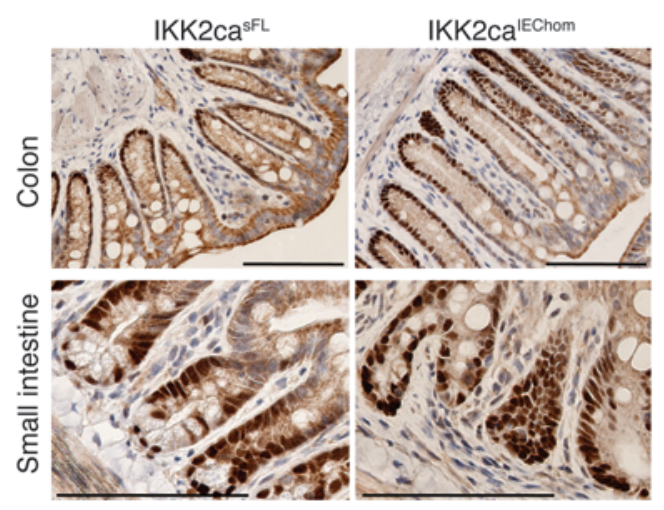

D

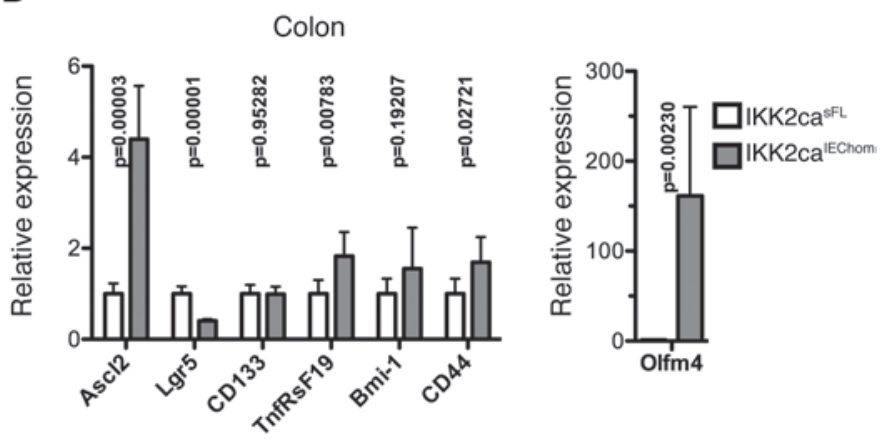

E

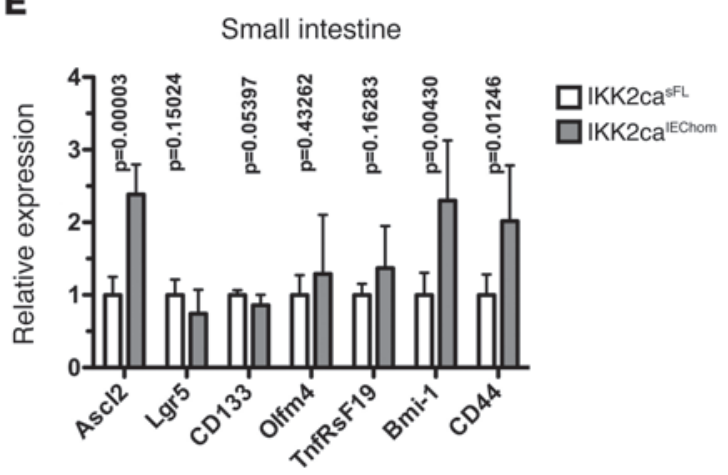

F

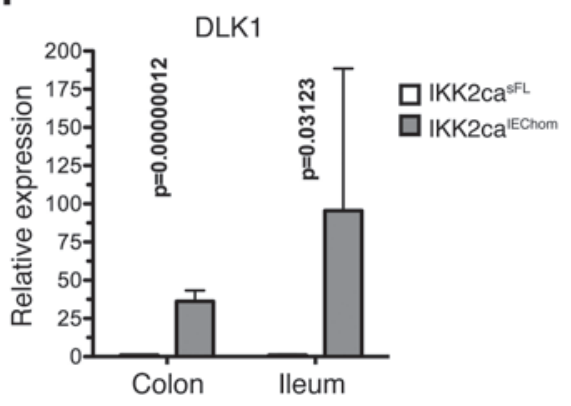

Figure 7

Increased $\beta$-catenin activation, hyperproliferation, and elevated stem cell factor expression in IECs from IKK2caIEChom mice. (A) Immunoblot analysis on cytoplasmic and nuclear extracts from colonic IECs showed increased levels of $\beta$-catenin and active $\mathrm{N}$ terminally nonphosphorylated $\beta$-catenin in 8-week-old IKK2caIEChom compared with IKK2casFL mice. (B) Immunofluorescent staining for Ki67 reveals increased IEC proliferation in the colon of 10-week-old IKK2calEChom mice, where the proliferating cells were extended toward the lumen. Whereas in control ileum, mainly the TA cells showed Ki67 staining, all crypt cells were Ki67+ in the ileum of IKK2calEChom mice. (C) Immunohistochemical staining revealed increased numbers of Sox9-expressing IECs in the colon and SI of 10-week-old IKK2calEChom compared with IKK2casFL mice. Paneth cells and stem cells were not identifiable with Sox9 staining in SI crypts from IKK2calEChom mice. (D and E) qRT-PCR analysis showed increased expression of intestinal stem cell factors in the colon (D) and in the SI (E) of 7- to 8-week-old IKK2calEChom mice compared with IKK2casFL littermates ( $n \geq 6$ per genotype; mRNA levels are presented as mean $\pm \mathrm{SD}$ ). (F) qRT-PCR analysis showed increased expression of DLK1 in the colon and in the ileum of 7- to 8-week-old IKK2calEChom mice compared with IKK2casFL littermates $(n \geq 6$ per genotype; mRNA levels are presented as mean \pm SD). Scale bars: $50 \mu \mathrm{m}$.

to induce the infiltration of myeloid cells and the activation of stromal fibroblasts, creating a microenvironment supporting tumor growth. However, it is unlikely that IKK2ca expression drives intestinal tumorigenesis only by inducing cytokine expression, as the chronic intestinal inflammation caused by increased TNF expression in a mouse model of severe Crohn disease was not sufficient to induce intestinal tumors (51).
The Wnt signaling pathway controls normal epithelial homeostasis, and mutations activating Wnt signaling cause intestinal tumors in humans and mice $(26,52,53)$. We therefore hypothesized that constitutive IKK2 activation in IECs might have an impact on Wht signaling to induce intestinal tumorigenesis. Indeed, we found that IECs in IKK2 $\mathrm{ca}^{\text {IEChom }}$ mice showed increased expression and activation of $\beta$-catenin already in a premalignant state, a surprising 
result considering previous studies reporting that IKK2 negatively regulates $\beta$-catenin activity (54). Although the precise mechanisms by which constitutive IKK $2 / \mathrm{NF}-\kappa \mathrm{B}$ signaling in IECs induces $\beta$-catenin activation are not fully understood at present, overexpression of IKK 2 ca could increase $\beta$-catenin activity by either cellintrinsic or paracrine functions. $\beta$-catenin activation in tumors is not controlled solely by Wnt ligands or mutations activating Wnt signaling, but additional Wnt-independent cues from the microenvironment are also required for full activation of $\beta$-catenin signaling $(52,55)$. Indeed, stromal myofibroblasts were recently shown to regulate $\beta$-catenin activation in colon cancer cells via the secretion of factors not related to Wnt ligands (56). In addition, macrophages have been shown to regulate $\beta$-catenin activation in tumor cells by secreting cytokines such as TNF and IL-1 $\beta$ (56-59). Macrophage-produced TNF activated Wnt signaling by inducing GSK3 $\beta$ phosphorylation in an NF- $\kappa B$-independent manner (57). Furthermore, IL- $1 \beta$ activated $\beta$-catenin via the NF- $\kappa B$-dependent induction of PDK1/Akt-mediated phosphorylation of GSK3 $\beta$ (59). IKK activation was also required for GSK3 $\beta$ phosphorylation and $\beta$-catenin activation in response to progastrin stimulation (60). Thus, constitutive IKK2 activation in IECs might also activate $\beta$-catenin in a cell-intrinsic manner by inducing PDK1/Akt-mediated phosphorylation of GSK3 $\beta$. In addition, since degradation of both $\beta$-catenin and IкB proteins is regulated by the $\beta$-TrCP E3 ubiquitin ligase (61), it is possible that high expression levels of constitutively active IKK2 inducing continuous phosphorylation and degradation of IKB proteins, as in the IECs of IKK2 $\mathrm{ca}^{\mathrm{IEChom}}$ mice, reduces $\beta$-TrCP availability for $\beta$-catenin degradation and in this way indirectly increases $\beta$-catenin activity.

The Wnt signaling pathway regulates the fate of intestinal crypt stem cells, which are the cells of origin of intestinal cancers $(37,62)$. We observed that all cells in the base of SI crypts, which in wildtype mice harbor rarely dividing stem cells and Paneth cells, stained strongly with Ki67 antibodies in IKK2 $\mathrm{ca}^{\mathrm{IEChom}}$ mice, suggesting that the crypt stem cells show increased proliferation in IKK2 $\mathrm{ca}^{\mathrm{IEChom}}$ mice. In addition, gene expression analysis in the intestine of $\mathrm{IKK} 2 \mathrm{ca}^{\mathrm{IEChom}}$ mice revealed increased expression of a number of stem cell-specific genes including Ascl2, Olfm4, CD44, TnfRsF19, and $B m i-1$. These alterations are likely to be linked with $\beta$-catenin activation in IECs from IKK2 $\mathrm{ca}^{\mathrm{IEChom}}$ mice, since Ascl2, TnfRsF19, and CD44 are $\beta$-catenin target genes (31). However, Olfm 4, Bmi-1, and CD44 are regulated by NF- $\mathrm{KB}(38-40)$. In addition, we found that the gene encoding Ascl2, a transcription factor controlling intestinal stem cell fate (31), contains an NF- $\kappa \mathrm{B}$ consensus site in its promoter suggesting that NF- $\kappa \mathrm{B}$ activation could also directly induce Ascl 2 expression. In addition, DLK1 was strongly upregulated in IECs overexpressing IKK2ca. Although DLK1 has not been directly associated with intestinal crypt stem cells, it is known to prevent preadipocyte differentiation by inducing the expression of Sox 9 and is thought to play a more general role in maintaining progenitor cells in different tissues in an undifferentiated state (41). Thus, the observed increase in Sox9 expression in IKK2ca-expressing IECs could be induced cooperatively by $\beta$-catenin and DLK1. DLK1 was also implicated in colorectal carcinogenesis (42), suggesting it could be directly implicated in intestinal tumorigenesis in IKK2 $\mathrm{ca}^{\mathrm{IEChom}}$ mice. Alterations in the intestinal stem cell compartment have not been reported in mice with epithelial-specific inhibition of NF- $\kappa B$ $(5,22,63)$, suggesting that impairment of NF- $\mathrm{\kappa B}$ activity might not be sufficient to alter intestinal stem cell homeostasis. However, constitutively increased NF- $\mathrm{KB}$ activation, such as in IKK2 $\mathrm{ca}^{\mathrm{IEChom}}$ mice or upon amplification of the Ikk2 genomic locus in human colorectal cancers (15), could affect the intestinal stem cell compartment and in this way contribute to intestinal tumorigenesis. In our experimental approach, IKK2ca is expressed under the control of the Rosa26 locus that drives strong expression in all cell types of the intestinal epithelium including crypt stem cells (64); therefore, we cannot address the specific contribution of stem cell-intrinsic $\mathrm{NF}-\kappa \mathrm{B}$ activation in intestinal tumorigenesis. Studies in new mouse models allowing stem cell-specific manipulation of NF-кB activity will be required to address the potential role of NF- $\kappa \mathrm{B}$ in intestinal epithelial stem cells.

Taken together, our results presented here show that constitutive IKK2 activation in premalignant epithelial cells is sufficient to initiate and sustain the full spectrum of cell-intrinsic and microenvironmental alterations that are required for intestinal tumorigenesis. While IKK2 ca expression strongly activated NF-KB, we cannot exclude that other NF-KB-independent functions induced by IKK2 contributed to intestinal tumorigenesis in this model. In addition to its well-established antiapoptotic function, IKK2 activation rendered tumor cells self-sufficient by providing them with the capacity to alter their microenvironment to support tumor growth. These findings provide experimental evidence that mutations activating IKK2/NF-KB signaling could have a causative role in carcinogenesis, although it remains to be investigated whether consti-

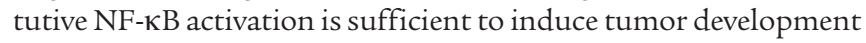
in tissues other than the intestinal epithelium. However, a recent unbiased large scale genomic analysis of somatic copy number alterations in human cancers revealed that members of the NF-кB signaling pathway, including IKK2, were frequently amplified in different cancer types (15), supporting a fundamental tumor cellintrinsic role of NF- $\kappa \mathrm{B}$ in carcinogenesis.

\section{Methods}

Mice. R26IKK2ca ${ }^{\mathrm{sFL}}$ (18), villinCre (19), and Apc1638N mice (29) have been described. Unless otherwise indicated, littermates carrying $\mathrm{R} 26 \mathrm{IKK} 2 \mathrm{ca}^{\mathrm{sFL}}$ alleles, but not the villin-Cre transgene, served as control mice for the described experiments. Animals were housed in individually ventilated cages in a specific pathogen-free mouse facility at the University of Cologne. All animal studies were approved by local governmental authorities (Landesamt für Natur, Umwelt und Verbraucherschutz Nordrhein-Westfalen, Germany).

Mouse experiments. DSS (MP, MW 36000-50000) was provided in the drinking water. AOM was administered via intraperitoneal injections at $10 \mathrm{mg} / \mathrm{kg}$. For endoscopy, mice were anesthetized with ketamine (Ratiopharm)/Rompun (Bayer), and a high-resolution miniendoscope, Coloview (Karl Storz), was used to determine the murine endoscopic index of colitis severity (murine endoscopic inflammatory colitis score [MEICS]) and to assess colonic tumorigenesis as previously described (65).

Histology. Tissues were fixed overnight in $4 \%$ paraformaldehyde, embedded in paraffin, and cut into $4-\mu \mathrm{m}$ sections. H\&E-stained sections were scored in a blinded fashion for the amount of inflammation, tissue damage, and/or tumorigenesis. For IHC staining, paraffin sections were rehydrated and heat-induced antigen retrieval was performed either in $10 \mathrm{mM}$ sodium citrate, $0.05 \%$ Tween-20, pH 6.0, or in $10 \mathrm{mM}$ Tris; 1 mM EDTA, pH 9.0. Primary antibodies were anti-Ki67 (Dako), anti-FLAG (Sigma-Aldrich), antiGr1 (BD Biosciences - Pharmingen), anti-F4/80 (clone A3-1), anti-B220 (clone RA3-6B2), anti-CD3 (Abcam), anti-Sox9 (Millipore), anti- $\beta$-catenin (BD Biosciences - BD Transduction Laboratories). Biotinylated secondary antibodies, $\mathrm{ABC}$ Kit Vectastain Elite, and DAB substrate (PerkinElmer, Vector, and Dako) were used. Incubation times with DAB were equal for 
all samples. For immunofluorescence, Alexa Fluor 488-coupled antibodies (Invitrogen) were used; nuclei were counterstained with DAPI (Roche). Pictures were taken with a fluorescence microscope (DM5500; Leica) at the same exposure and intensity settings for all systems analyzed.

IEC isolation and immunoblotting. IECs were isolated by sequential incubation of intestinal tissue in $1 \mathrm{mM}$ DTT and $1.5 \mathrm{mM}$ EDTA solutions as described previously (66). For total extracts. cells were lysed in high-salt RIPA buffer (20 mM HEPES, pH 7.6; $350 \mathrm{mM} \mathrm{NaCl} ; 20 \%$ glycerol; $1 \mathrm{mM}$ $\mathrm{MgCl}_{2} ; 0.5$ mM EDTA; 0.1 mM EGTA; $1 \% \mathrm{NP}-40$ ) for 30 minutes on ice. For the preparation of cytoplasmic extracts, cells were lysed in hypotonic lysis buffer (10 mM HEPES, pH 7.6; 10 mM KCl; 2 mM MgCl $2 ; 0.1$ mM EDTA) on ice, and the nuclear extract was recovered by lysis under high-salt conditions (50 mM HEPES, pH 7.8; 50 mM KCl; 300 mM NaCl; 0,1 mM EDTA; $10 \%$ glycerol). Protease inhibitor cocktail and PhosSTOP (Roche) were added prior to use. Protein extracts were separated by $10 \%$ SDS-PAGE and transferred to Immobilon-P PVDF membranes (Millipore). Membranes were probed with primary antibodies anti-IKK2 (rabbit monoclonal; Cell Signaling), anti-IKK1 and anti-p100 (rabbit; Cell Signaling), anti-NEMO (rabbit; made in our laboratory; ref. 14), anti-IкB $\alpha$ (rabbit; Santa Cruz Biotechnology Inc.), anti-p65 and anti-RelB (rabbit; Santa Cruz Biotechnology Inc.), anti-FLAG M2 peroxidase-coupled (mouse; Sigma-Aldrich), anti- $\alpha$-tubulin (mouse; Sigma-Aldrich), anti-IL-1 $\beta$ (rabbit; Abcam) anti$\beta$-catenin (mouse; BD Biosciences - BD Transduction Laboratories), antiactive $\beta$-catenin (mouse; Millipore), anti- $\beta$-actin (goat; Santa Cruz Biotechnology Inc.), and anti-lamin A/C (goat; Santa Cruz Biotechnology Inc.). Membranes were then incubated with secondary HRP-coupled antibodies (GE Healthcare and Jackson ImmunoResearch) and developed with chemiluminescent detection substrate (GE Healthcare and Thermo Scientific).

EMSA. Nuclear IEC extracts were prepared as described previously (67). An NF-kB consensus probe ( $5^{\prime}$-AGTTGAGGGGACTTTCCCAGGC-3') was 5 -labeled with IR-Dyes (Li-Cor Biosciences) and detected with the Odyssey Infrared System.

qRT-PCR. Total RNA was extracted with Trizol Reagent (Invitrogen) and RNeasy Columns (QIAGEN), and cDNA was prepared with Superscript III cDNA-synthesis Kit (Invitrogen). qRT-PCR was performed with SYBR Green or TaqMan analysis (Applied Biosystems). Gapdh, Villin, and TATABox binding protein (TBP) were used as reference genes.

TaqMan probes and primer sequences used for $q R T-P C R$. TaqMan probes were as follows: Cxcl1, Mm00433859_m1; Cxcl10, Mm00445235_m1; Cxcl-16, Mm00469712_m1; Ccl20, Mm00444228_m1; TNF, Mm00443258_m1; MCP-1, Mm00441242_m1; IL-1ß, Mm00434228_m1; IL-6, Mm00446190_ m1; IL-12 p35, Mm00434165_m1; IL-12 p40, Mm99999067_m1; IL-23 p19, Mm00518984_m1; IL-17F, Mm00521423_m1; TGF-b1, Mm03024053_m1; Cox2, Mm00478374_m1; TSLP, Mm00498739_m1; Ascl2,Mm01268891_g1;Olfm4, Mm01320260_m1; DLK1, Mm00494477_ m1; Lgr5, Mm00438890_m1; CD133, Mm00477115_m1; Gapdh, Mm99999915_g1; TATA box binding protein; and Mm00446973_m1.

Primer sequences for SYBR Green qRT-PCR were obtained from PrimerBank (http://pga.mgh.harvard.edu/primerbank/index.html): Bmi-1 for TATAACTGATGATGAGATAATAAGC, rev ATAAGTGGTTACAGGAAGTC; TnfRsF19 for ATTCTCTTCCTACTCCACCTG, rev CATAGCCGAAGCCACATTC; CD44 for TCTGCCATCTAGCACTAAGAGC, rev GTCTGGGTATTGAAAGGTGTAGC; IKK2 for CTGAagAtCGCCTGTAGCAAA, rev TCCATCTGTAACCAGCTCCAG; IKK1 for GTCAGGACCGTGTTCTCAAGG, rev GCTTCTTTGATGTTACTGAGGGC; c-myc for ATGCCCCTCAACGTGAACTTC, rev CGCAACATAGGATGGAGAGCA; cyclin D1 for GCGTACCCTGACACCAATCTC, rev CTCCTCTTCGCACTTCTGCTC; MMP7 for CTGCCACTGTCCCAGGAAG, rev GGGAGAGTTTTCCAGTCATGG; villin for TCAAAGGCTCTCTCAACATCAC, rev AGCAGTCACCATCGAAGAAGC; Gapdh for CATGTTCCAGTATGACTCCACTC, rev GGCCTCACCCCATTTGATGT.

Statistics. All data shown represent the mean \pm SD. Statistical analyses were performed using unpaired 2-tailed Student's $t$ tests with unequal variance. $P<0.05$ was considered significant.

\section{Acknowledgments}

We wish to thank C. Uthoff-Hachenberg, J. Pfeiffer, E. Mahlberg, D. Beier, J. Buchholz, B. Huelser, and B. Wolff for excellent technical assistance. We also thank Alan Clarke for valuable discussions. This work was supported by the European Commission FP7 program grant INFLA-CARE (EC contract number 223151) and by grants from the Deutsche Forschungsgemeinschaft to M. Pasparakis.

Received for publication October 7, 2010, and accepted in revised form April 6, 2011.

Address correspondence to: Manolis Pasparakis, Institute for Genetics, University of Cologne, Zülpicher Str. 47a, D-50674 Cologne, Germany. Phone: 49.221.470.1526; Fax: 49.221.470.5163; E-mail: pasparakis@uni-koeln.de.
1. Staudt LM. Oncogenic activation of NF-kappaB. Cold Spring Harb Perspect Biol. 2010;2(6):a000109.

2. Yang J, et al. Conditional ablation of Ikkb inhibits melanoma tumor development in mice. J Clin Invest. 2010;120(7):2563-2574.

3. Pikarsky E, et al. NF-kappaB functions as a tumour promoter in inflammation-associated cancer. Nature. 2004;431(7007):461-466.

4. Meylan E, et al. Requirement for NF-kappaB signalling in a mouse model of lung adenocarcinoma. Nature. 2009;462(7269):104-107.

5. Greten FR, et al. IKKbeta links inflammation and tumorigenesis in a mouse model of colitis-associated cancer. Cell. 2004;118(3):285-296.

6. Sakamoto K, et al. Inhibitor of kappaB kinase beta regulates gastric carcinogenesis via interleukin-1alpha expression. Gastroenterology. 2010; 139(1):226-238.e226.

7. Mantovani A, Allavena P, Sica A, Balkwill F. Cancer-related inflammation. Nature. 2008; 454(7203):436-444.

8. Grivennikov SI, Greten FR, Karin M. Immunity, inflammation, and cancer. Cell. 2010; 140(6):883-899.
9. Erez N, Truitt M, Olson P, Arron ST, Hanahan D. Cancer-associated fibroblasts are activated in incipient neoplasia to orchestrate tumor-promoting inflammation in an NF-kappaB-dependent manner. Cancer Cell. 2010;17(2):135-147.

10. Basseres DS, Ebbs A, Levantini E, Baldwin AS. Requirement of the NF-kappaB subunit p65/RelA for K-Ras-induced lung tumorigenesis. Cancer Res. 2010;70(9):3537-3546.

11. Dajee M, et al. NF-kappaB blockade and oncogenic Ras trigger invasive human epidermal neoplasia. Nature. 2003;421(6923):639-643.

12. van Hogerlinden M, Rozell BL, Ahrlund-Richter L, ToftgÅrd R. Squamous cell carcinomas and increased apoptosis in skin with inhibited Rel/ nuclear factor-kappaB signaling. Cancer Research. 1999;59(14):3299-3303.

13. Maeda S, Kamata H, Luo JL, Leffert H, Karin M IKKbeta couples hepatocyte death to cytokinedriven compensatory proliferation that promotes chemical hepatocarcinogenesis. Cell. 2005;121(7):977-990.

14. Luedde T, et al. Deletion of NEMO/IKKgamma in liver parenchymal cells causes steatohepati- tis and hepatocellular carcinoma. Cancer Cell. 2007;11(2):119-132.

15. Beroukhim R, et al. The landscape of somatic copynumber alteration across human cancers. Nature. 2010;463(7283):899-905

16. Prasad S, Ravindran J, Aggarwal BB. NF-kappaB and cancer: how intimate is this relationship. $\mathrm{Mol}$ Cell Biochem. 2010;336(1-2):25-37.

17. Karin $M$. Nuclear factor-kappaB in cancer development and progression. Nature. 2006; 441(7092):431-436.

18. Sasaki Y, et al. Canonical NF-kappaB activity, dispensable for B cell development, replaces BAFFreceptor signals and promotes B cell proliferation upon activation. Immunity. 2006;24(6):729-739.

19. Madison BB, Dunbar L, Qiao XT, Braunstein K, Braunstein E, Gumucio DL. Cis elements of the villin gene control expression in restricted domains of the vertical (crypt) and horizontal (duodenum, cecum) axes of the intestine. J Biol Chem. 2002;277(36):33275-33283.

20. Lombardi L, et al. Structural and functional characterization of the promoter regions of the NFKB2 gene. Nucleic Acids Res. 1995;23(12):2328-2336. 
21. Bren GD, Solan NJ, Miyoshi H, Pennington KN, Pobst LJ, Paya CV. Transcription of the RelB gene is regulated by NF-kappaB. Oncogene. 2001;20(53):7722-7733.

22. Steinbrecher KA, Harmel-Laws E, Sitcheran R, Baldwin AS. Loss of epithelial RelA results in deregulated intestinal proliferative/apoptotic homeostasis and susceptibility to inflammation. J Immunol. 2008;180(4):2588-2599.

23. Nambiar PR, Girnun G, Lillo NA, Guda K, Whiteley HE, Rosenberg DW. Preliminary analysis of azoxymethane induced colon tumors in inbred mice commonly used as transgenic/knockout progenitors. Int J Oncol. 2003;22(1):145-150.

24. Neufert C, Becker C, Neurath MF. An inducible mouse model of colon carcinogenesis for the analysis of sporadic and inflammation-driven tumor progression. Nat Protoc. 2007;2(8):1998-2004.

25. Barker N, Clevers H. Catenins, Wnt signaling and cancer. Bioessays. 2000;22(11):961-965.

26. Miyoshi Y, et al. Somatic mutations of the APC gene in colorectal tumors: mutation cluster region in the APC gene. Hum Mol Genet. 1992;1(4):229-233.

27. Su LK, et al. Multiple intestinal neoplasia caused by a mutation in the murine homolog of the APC gene. Science. 1992;256(5057):668-670.

28. Fodde R. The APC gene in colorectal cancer. Eur J Cancer. 2002;38(7):867-871.

29. Fodde R, et al. A targeted chain-termination mutation in the mouse Apc gene results in multiple intestinal tumors. Proc Natl Acad Sci U S A. 1994;91(19):8969-8973.

30. Blache P, et al. SOX9 is an intestine crypt transcription factor, is regulated by the Wnt pathway, and represses the CDX2 and MUC2 genes. J Cell Biol. 2004;166(1):37-47.

31. van der Flier LG, et al. Transcription factor achaete scute-like 2 controls intestinal stem cell fate. Cell. 2009;136(5):903-912.

32. van Es JH, et al. Wnt signalling induces maturation of Paneth cells in intestinal crypts. Nat Cell Biol. 2005;7(4):381-386.

33. Barker N, van de Wetering $M$, Clevers $H$. The intestinal stem cell. Genes Dev. 2008;22(14):1856-1864.

34. Crawford HC, et al. The metalloproteinase matrily$\sin$ is a target of beta-catenin transactivation in intestinal tumors. Oncogene. 1999;18(18):2883-2891.

35. Bastide $\mathrm{P}$, et al. Sox9 regulates cell proliferation and is required for Paneth cell differentiation in the intestinal epithelium. J Cell Biol. 2007;178(4):635-648

36. Barker N, Clevers H. Leucine-rich repeat-containing G-protein-coupled receptors as markers of adult stem cells. Gastroenterology. 2010;138(5):1681-1696.

37. Barker N, et al. Crypt stem cells as the cells-of-origin of intestinal cancer. Nature. 2009;457(7229):608-611.

38. Hinz M, et al. Nuclear factor kappaB-dependent gene expression profiling of Hodgkin's disease tumor cells, pathogenetic significance, and link to constitutive signal transducer and activator of transcription 5a activity. J Exp Med. 2002;196(5):605-617.

39. Chin KL, et al. The regulation of OLFM4 expression in myeloid precursor cells relies on NF-kappaB transcription factor. BrJ Haematol. 2008;143(3):421-432.

40. Dutton A, et al. Bmi-1 is induced by the EpsteinBarr virus oncogene LMP1 and regulates the expression of viral target genes in Hodgkin lymphoma cells. Blood. 2007;109(6):2597-2603.

41. Sul HS. Minireview: Pref-1: role in adipogenesis and mesenchymal cell fate. Mol Endocrinol. 2009;23(11):1717-1725

42. Dong M, et al. Azoxymethane-induced pre-adipocyte factor 1 (Pref-1) functions as a differentiation inhibitor in colonic epithelial cells. Carcinogenesis. 2004;25(11):2239-2246

43. Becker C, et al. TGF-beta suppresses tumor progression in colon cancer by inhibition of IL- 6 transsignaling. Immunity. 2004;21(4):491-501.

44. Bollrath J, et al. gp130-mediated Stat 3 activation in enterocytes regulates cell survival and cell-cycle progression during colitis-associated tumorigenesis. Cancer Cell. 2009;15(2):91-102.

45. Grivennikov S, et al. IL-6 and Stat 3 are required for survival of intestinal epithelial cells and development of colitis-associated cancer. Cancer Cell. 2009;15(2):103-113.

46. Popivanova BK, et al. Blocking TNF-alpha in mice reduces colorectal carcinogenesis associated with chronic colitis. J Clin Invest. 2008;118(2):560-570.

47. Dinarello CA. Why not treat human cancer with interleukin-1 blockade? Cancer Metastasis Rev. 2010;29(2):317-329.

48. Ghadjar P, Rubie C, Aebersold DM, Keilholz U. The chemokine CCL20 and its receptor CCR6 in human malignancy with focus on colorectal cancer. Int J Cancer. 2009;125(4):741-745.

49. Darash-Yahana M, et al. The chemokine CXCL16 and its receptor, CXCR6, as markers and promoters of inflammation-associated cancers. PLOS ONE. 2009;4(8):e6695

50. Franco OE, Shaw AK, Strand DW, Hayward SW. Cancer associated fibroblasts in cancer pathogenesis. Semin Cell Dev Biol. 2010;21(1):33-39.

51. Kontoyiannis D, Pasparakis M, Pizarro TT, Cominelli F, Kollias G. Impaired on/off regulation of TNF biosynthesis in mice lacking TNF AU-rich elements: implications for joint and gut-associated immunopathologies. Immunity. 1999;10(3):387-398.
52. Fodde R, Brabletz T. Wnt/beta-catenin signaling in cancer stemness and malignant behavior. Curr Opin Cell Biol. 2007;19(2):150-158.

53. Clevers $\mathrm{H}$. Wnt/beta-catenin signaling in development and disease. Cell. 2006;127(3):469-480.

54. Lamberti C, et al. Regulation of beta-catenin function by the IkappaB kinases. J Biol Chem. 2001;276(45):42276-42286.

55 . Brabletz T, et al. Variable beta-catenin expression in colorectal cancers indicates tumor progression driven by the tumor environment. Proc Natl Acad Sci US A. 2001;98(18):10356-10361.

56. Vermeulen L, et al. Wnt activity defines colon cancer stem cells and is regulated by the microenvironment. Nat Cell Biol. 2010;12(5):468-476.

57. Oguma K, et al. Activated macrophages promote Wnt signalling through tumour necrosis factor-alpha in gastric tumour cells. EMBO J. 2008; 27(12):1671-1681.

58. Kaler P, Augenlicht L, Klampfer L. Macrophagederived IL-1beta stimulates Wnt signaling and growth of colon cancer cells: a crosstalk interrupted by vitamin D3. Oncogene. 2009;28(44):3892-3902.

59. Kaler P, Godasi BN, Augenlicht L, Klampfer L. The NF-kappaB/AKT-dependent induction of Wnt signaling in colon cancer cells by macrophages and IL-1beta. Cancer Microenviron. 2009;2(1):69-80.

60. Umar S, Sarkar S, Wang Y, Singh P. Functional crosstalk between beta-catenin and NFkappaB signaling pathways in colonic crypts of mice in response to progastrin. J Biol Chem. 2009;284(33):22274-22284.

61. Fuchs SY, Spiegelman VS, Kumar KG. The many faces of beta-TrCP E3 ubiquitin ligases: reflections in the magic mirror of cancer. Oncogene. 2004;23(11):2028-2036.

62. Li L, Clevers H. Coexistence of quiescent and active adult stem cells in mammals. Science. 2010; 327(5965):542-545.

63. Nenci A, et al. Epithelial NEMO links innate immunity to chronic intestinal inflammation. Nature. 2007;446(7135):557-561.

64. Zhu L, et al. Prominin 1 marks intestinal stem cells that are susceptible to neoplastic transformation. Nature. 2009;457(7229):603-607.

65 . Becker $\mathrm{C}$, et al. In vivo imaging of colitis and colon cancer development in mice using high resolution chromoendoscopy. Gut. 2005;54(7):950-954.

66. Ukena SN, et al. Probiotic Escherichia coli Nissle 1917 inhibits leaky gut by enhancing mucosal integrity. PLoS ONE. 2007;2(12):e1308.

67. Schmidt-Supprian M, et al. NEMO/IKK gammadeficient mice model incontinentia pigmenti. $\mathrm{Mol}$ Cell. 2000;5(6):981-992. 